\title{
Pacific decadal oscillation remotely forced by the equatorial Pacific and the Atlantic Oceans
}

\author{
Zachary F. Johnson $^{1}$ (D) $\cdot$ Yoshimitsu Chikamoto ${ }^{1} \cdot$ S.-Y. Simon Wang ${ }^{1} \cdot$ Michael J. McPhaden $^{2} \cdot$ Takashi Mochizuki $^{3,4}$
}

Received: 27 September 2019 / Accepted: 13 May 2020 / Published online: 6 June 2020

(c) The Author(s) 2020

\begin{abstract}
The Pacific Decadal Oscillation (PDO), the leading mode of Pacific decadal sea surface temperature variability, arises mainly from combinations of regional air-sea interaction within the North Pacific Ocean and remote forcing, such as from the tropical Pacific and the Atlantic. Because of such a combination of mechanisms, a question remains as to how much PDO variability originates from these regions. To better understand PDO variability, the equatorial Pacific and the Atlantic impacts on the PDO are examined using several 3-dimensional partial ocean data assimilation experiments conducted with two global climate models: the CESM1.0 and MIROC $3.2 \mathrm{~m}$. In these partial assimilation experiments, the climate models are constrained by observed temperature and salinity anomalies, one solely in the Atlantic basin and the other solely in the equatorial Pacific basin, but are allowed to evolve freely in other regions. These experiments demonstrate that, in addition to the tropical Pacific's role in driving PDO variability, the Atlantic can affect PDO variability by modulating the tropical Pacific climate through two proposed processes. One is the equatorial pathway, in which tropical Atlantic sea surface temperature (SST) variability causes an El Niño-like SST response in the equatorial Pacific through the reorganization of the global Walker circulation. The other is the north tropical pathway, where low-frequency SST variability associated with the Atlantic Multidecadal Oscillation induces a Matsuno-Gill type atmospheric response in the tropical Atlantic-Pacific sectors north of the equator. These results provide a quantitative assessment suggesting that $12-29 \%$ of PDO variance originates from the Atlantic Ocean and $40-44 \%$ from the tropical Pacific. The remaining $27-48 \%$ of the variance is inferred to arise from other processes such as regional ocean-atmosphere interactions in the North Pacific and possibly teleconnections from the Indian Ocean.
\end{abstract}

Keywords $\mathrm{PDO} \cdot \mathrm{AMO} \cdot$ Multidecadal variability $\cdot$ Climate model $\cdot$ ENSO

\section{Introduction}

The Pacific Decadal Oscillation (PDO) is the dominant low frequency climate variability in the North Pacific and is defined as the leading mode of North Pacific detrended sea surface temperature anomalies (SSTAs) $\left(20^{\circ}-70^{\circ} \mathrm{N}\right)$

Zachary F. Johnson

zfjohnson@aggiemail.usu.edu

1 Department of Plants, Soils, and Climate, Utah State University, 4820 Old Main Hill, Logan UT 84322, USA

2 Pacific Marine Environmental Laboratory/NOAA, Seattle, WA, USA

3 Department of Earth and Planetary Sciences, Kyushu University, Fukuoka, Japan

4 Japan Agency for Marine-Earth Science and Technology, Yokohama, Japan calculated by a statistical decomposition called empirical orthogonal functions (EOFs) (Mantua et al. 1997; Minobe 1997; Zhang and Levitus 1997). The positive (negative) phase of the PDO is characterized by cool (warm) sea surface temperatures (SSTs) in the Kuroshio-Oyashio Extension (KOE) region and its surrounding warm (cool) SSTs along the west coast of North America (Mantua and Hare 2002; Qiu 2002; Newman et al. 2016). Associated with these physical ocean changes, the coherent decadal variability is also observed in marine ecosystems and biogeochemical cycles in the North Pacific, such as decadal shifts in fish production, plankton biomass, and nutrient concentrations (Francis and Hare 1994; Mantua and Hare 2002; Chavez et al. 2003). In addition to these regional changes, the PDO has shown remote associations through atmospheric teleconnections with multi-decadal drought and pluvial conditions over the United States, Canada, Siberia, Australia, and 
northern South America (Barlow et al. 2001; Tanimoto et al. 2003; McCabe et al. 2004; Hu and Huang 2009; Zanchettin et al. 2008; Wang et al. 2009; Taguchi et al. 2012; Wang et al. 2014; Vance et al. 2015). From the perspective of these broad impacts, improving our understanding of PDO mechanisms is essential, not only for enhancing PDO predictability, but also for extending its application to marine ecosystem predictions (Mochizuki et al. 2010; Chikamoto et al. 2013; Kim et al. 2014; Chikamoto et al. 2015a).

Two processes mainly characterize PDO mechanisms: regional air-sea interactions in the North Pacific and remote forcings from other ocean regions (Kwon and Deser 2007; Liu and Alexander 2007; Newman et al. 2016), such as the tropical Pacific and Atlantic. While it is challenging to separate regional air-sea interactions and remote impacts on the PDO due to feedback mechanisms (Zhang and Delworth 2015), there is a scientific consensus that ENSO variability is the primary forcing for the PDO on interannual timescales through the "atmospheric bridge" and subsequent changes in Aleutian low variability (Trenberth et al. 1998; Alexander et al. 2004; Strong and Magnusdottir 2009). Despite the previous research on the atmospheric bridge process through many observational analyses and modeling experiments (Alexander 1990; Lau and Nath 1994, 1996; Nakamura et al. 1997; Barlow et al. 2001; Deser et al. 2004), there is large model uncertainty regarding timing and strength of the ENSO-PDO relationship. In simulations from the Coupled Model Intercomparison Project (CMIP), maximum correlation coefficients of the ENSO-PDO relationship in pre-industrial control simulations range from $0.2-0.9$ (Nidheesh et al. 2017), which covers the observational estimate $(\sim 0.6)$, yet there is still significant model diversity (Alexander et al. 2008; Hu and Huang 2009). In addition to strength, the time lag between the ENSO and PDO indices in CMIP3 and CMIP5 models ranges from almost instantaneous to 8 months with most CMIP models having a 4-8 month lag. As a result, there is still large uncertainty in the current estimate of PDO variability originating from the tropical Pacific, which ranges from 25-50\% of PDO variance. However, some of the uncertainty may simply be internal variability (Alexander et al. 2002, 2010; Zhang et al. 2018).

Uncertainty of the ENSO-PDO relationship may also come from the Atlantic remote forcing through inter-basin interactions. Recent studies pointed out that Atlantic decadal variability can affect tropical Pacific climate variability through a modulation of the global Walker circulation (Rodríguez-Fonseca et al. 2009; Kucharski et al. 2011; Chikamoto et al. 2012; McGregor et al. 2014; Kucharski et al. 2016; Li et al. 2015; Cai et al. 2019). On interannual timescales, ENSO is also modulated by Atlantic SST variability through the north tropical Atlantic and the Atlantic Niño (Rodríguez-Fonseca et al. 2009; Luo et al. 2010; Ding et al. 2012; Ham et al. 2013a, b; Luo et al. 2017; Cai et al. 2019).
Interestingly, most CMIP3 and CMIP5 models capture the inter-basin impact from the Atlantic to the Pacific, although the strength of the atmospheric response to Atlantic SST variability and the subsequent ENSO amplitude show vast diversity among the models (Ham and Kug 2015).

The mechanisms of the Atlantic impact on the PDO are still under debate, but three major processes have been proposed: inter-basin interactions, midlatitude jet stream activity, and an Arctic Ocean process through the Bering Strait. As described above, Atlantic Ocean variability can affect the frequency and amplitude of ENSO events through tropical inter-basin interactions (Ham and Kug 2015), which subsequently influences the PDO through the atmospheric bridge (Alexander 1990). Consistent with this mechanism, Levine et al. (2018) found that a positive Atlantic Multidecadal Oscillation (AMO) can favor a northward shift in the intertropical convergence zone (ITCZ) through changes in equatorial trade winds and precipitation anomalies, which then affect tropical Pacific SSTs. A similar inter-basin connection through a zonal circulation, but in the mid-latitude region instead of the tropics, was also proposed based on the mid-latitude sea level pressure (SLP) see-saw between the North Atlantic and North Pacific associated with the AMO (Sun et al. 2017; Gong et al. 2020). By contrast to these inter-basin interactions, other studies proposed that the AMO can affect the PDO through midlatitude jet stream activities (Zhang and Delworth 2007; Wu et al. 2011; Okumura et al. 2009). In this midlatitude process, three pathways are still under debate: a meridional shift in the midlatitude westerlies between the North Atlantic and Pacific (Zhang and Delworth 2007), changes in the Arctic Oscillation originating from North Atlantic SSTs (Zhang and Zhao 2015), and circumglobal Rossby wave propagation from the tropical Atlantic to the North Pacific via the South Asian jet (Okumura et al. 2009; Wu et al. 2011). The third process is through the Arctic and Bering Strait by introducing freshwater forcing in the Atlantic Meridional Overturning Circulation (AMOC) (Okumura et al. 2009). Because of these inter-basin and atmosphere-ocean interactions, appropriate modeling experiments using a fully coupled atmosphereocean general circulation model (AOGCM) are required to evaluate the most prominent pathway from the Atlantic to the North Pacific.

Whereas just a few studies simulated an Atlantic origin for PDO variability, many models captured the equatorial Pacific impact on the PDO through the atmospheric bridge process, including CMIP, Atmospheric Model Intercomparison Project (AMIP), mixed-layer, partial decoupling, pacemaker, and partial assimilation experiments. In the 1990s, AGCM experiments prescribing observed SST variability (so-called AMIP-type experiment; Lau and Nath 1994) evaluated the direct atmospheric responses to the tropical Pacific SST forcing. In the following papers, a role of 
thermodynamical air-sea interaction in the North Pacific was further assessed with subsequent AMIP-type experiments coupled with mixed-layer ocean models (e.g., Lau and Nath 1996; Alexander et al. 2002; Di Lorenzo et al. 2015). To assess a role of fully dynamical atmosphere-ocean interactions, Wang et al. (2012) proposed the partial decoupling experiment using the NCEP CFSv2 model, where SSTs are dampened toward climatological states in a targeted region, yet it was still challenging to isolate the remote ENSO impact on the PDO from regional air-sea interaction. To identify the climate variability originating from the tropical Pacific, a pacemaker experiment was proposed, in which the observed SST variability in the eastern tropical Pacific was prescribed in the ocean component of a climate model through heat flux forcing at the ocean surface (Kosaka and Xie 2013). In these experiments, the ocean and atmosphere are able to evolve freely outside the region but can also interact inside the targeted region. Using this pacemaker experiment, Zhang et al. (2018) demonstrated the atmospheric bridge concept, which is consistent with previous studies.

While the atmospheric bridge process from the tropical to the North Pacific has been well simulated by prescribing SST-only forcing into atmospheric general circulation models (AGCMs), a model experiment to capture the Atlantic impacts on the PDO is more challenging due to complicated ocean dynamics relating to the AMOC variability, which may introduce systematic errors in the Atlantic (Zhang and Zhao 2015). Previous studies constrained the Atlantic Ocean using SST-only in idealized experiments by prescribing the AMO-induced SST pattern (Ruprich-Robert et al. 2017; Levine et al. 2018) or a pacemaker experiment targeted in the Atlantic (Ding et al. 2012). However, Boer et al. (2016) pointed out that pacemaker experiments forced by Atlantic SSTs may introduce energy and density imbalances due to a lack of salinity information, which causes artificial changes in atmosphere-ocean interactions and can alter the coupled model equilibrium. A recent study by Chikamoto et al. (2019) demonstrated that 3-dimensional ocean temperature and salinity information is required to constrain the Atlantic in simulating AMOC variability. To minimize the aforementioned artificial changes in the AOGCM, the partial assimilation approach is implemented here, in which 3-dimensional temperature and salinity anomalies in the targeted region are assimilated into the climate model. In this partial assimilation approach, the model-simulated climate variability corresponds to the potential predictability if the model could perfectly predict ocean variability in the assimilated region. Using this partial assimilation approach, Johnson et al. (2018) identified an Atlantic modulation on Australian precipitation variability in the interannual-to-decadal timescale.

To more quantitatively assess how much of PDO variability originates from the equatorial Pacific and Atlantic basins, we conduct partial ocean data assimilation experiments using two state-of-the-art global climate models: the Community Earth System Model (CESM1.0) and the Model for Interdisciplinary Research on Climate (MIROC3.2m). By assimilating observed conditions in the global, equatorial Pacific, or Atlantic Oceans, respectively, we can evaluate how much each ocean basin contributes to the PDO variability. More detailed model experiments and their validations are described in Sects. 2 and 3. We then describe impacts from the tropical Pacific (Sect. 4) and the Atlantic on the PDO (Sect. 5), followed by a discussion (Sect. 6) and concluding remarks (Sect. 7).

\section{Data and model experiments}

\subsection{Observations}

This study examines observational SST datasets from the UK Met Office's HadSST version 3 for 1950-2014 (Kennedy et al. 2011a, b), the National Centers for Environmental Prediction's (NCEP) Extended Reconstructed Sea Surface Temperature version 4 (ERSSTv4) for 1960-2014 (Huang et al. 2015), and an objective ocean analysis compiled by the Japanese Meteorological Agency (JMA) (hereafter, referred to as ProjD) for 1950-2010 (Ishii and Kimoto 2009). In addition, we use SLP datasets derived from HadSLP version 3 for 1950-2014, JMA's JRA55 for 1960-2014 (Ebita et al. 2011), and NCEP derived SLP for 1960-2010. The analysis periods in ERSST/JRA55 and ProjD/NCEP are identical to those in the assimilation runs in the CESM and MIROC, respectively, while the HadSST/HadSLP spans both model time periods. By choosing these time periods, we can validate our model simulated SSTs and its associated air-sea interaction, as described in Sect. 3. For the observational datasets, the linear trends at each grid point are removed from the anomalies in order to remove the climate response to the radiative forcing (i.e., the global warming component). The linear detrend method is not perfect for removing the climate response to radiative forcing (Dong and McPhaden 2017), but its impact is minor, as described in Sect. 3 (Model validation).

\subsection{Models}

This study uses two fully-coupled AOGCMs: the CESM1.0 (Shields et al. 2012) and the MIROC3.2m (Nozawa et al. 2007). The CESM consists of 4 physical components for atmosphere, land, ocean, and sea ice (Hunke and Lipscomb 2008; Smith et al. 2010; Lawrence et al. 2012; RodríguezFonseca et al. 2009; Holland et al. 2012; Neale et al. 2013). The atmosphere and land models are T31 horizontal resolution (approximately $3.75^{\circ}$ ) with 26 atmospheric vertical levels. The ocean and sea-ice models use a horizontal 
resolution of approximately $3^{\circ}$ with a displaced North Pole and 60 ocean layers. The meridional grid in the equatorial region is approximately $1^{\circ}$ and the zonal grid is $3^{\circ}$. Details of the model's basic performance in the configuration can be found in Shields et al. (2012) and Chikamoto et al. (2015c).

In the MIROC, atmospheric and land models use a T42 spectral horizontal grid (approximately $2.8^{\circ}$ ) while the ocean and sea-ice components of the MIROC use 43 vertical levels with a zonal resolution approximately $1.41^{\circ}$. Its meridional grid is about $0.56^{\circ}$ in the equatorial region but $1.4^{\circ}$ at high latitudes. The physical processes in the ocean model of the MIROC include parameterizations for vertical convection and mixing, lateral mixing of momentum and tracer, and vertical penetration of shortwave radiation. All components of the atmosphere, ocean, land, and sea-ice modules are coupled without any flux corrections for exchanging heat, water, and momentum fluxes between the atmosphere and ocean. Details of the performance and configuration are found in Nozawa et al. (2007).

\subsection{Partial assimilation experiments}

Using these models, we first conducted two model experiments: a historical run and a global ocean assimilation run (GLOB run). In the historical run, the model was prescribed by time-varying observed natural and anthropogenic radiative external forcings (solar, aerosols, land-use change, and greenhouse gases) from 1850 to 2005. After 2005, we prescribed the RCP4.5 emission scenario for the CESM and an A1B-type scenario for the MIROC. These experiments consist of 10 ensemble members from initial conditions compiled from 10 random years of pre-industrial control simulations. Historical runs for each model correspond to the externally forced component due to radiative forcing. In the GLOB run, we prescribed the same radiative forcings as the historical run but assimilated 3-dimensional observed ocean temperature and salinity anomalies into the global climate models, which also consist of 10 ensemble members. The assimilated observed ocean data was derived from the ECMWF ocean reanalysis product (version 4) for 1958-2014 (Balmaseda et al. 2013) in the CESM run and the ProjD dataset for 1945-2010 (Ishii and Kimoto 2009) in the MIROC run. The reason for the difference in assimilated reanalysis products is because the CESM and MIROC were developed by different institutions, which are summarized in Table 1. In these observation-based datasets, the monthly mean was linearly interpolated into daily values. Next, analysis increments are estimated from a temporally, spatially, and vertically invariant model-to-observation ratio in analysis errors and added as forcing into the model's temperature and salinity equations during the analysis interval of one day by an Incremental Analysis Update scheme (Bloom et al. 1996; Huang et al. 2002).
Table 1 Summary of model experiments

\begin{tabular}{lll}
\hline Name & Assimilated region & Period \\
\hline CESM & & \\
GLOB & Global oceans & $1960-2014$ \\
eqPAC & Equatorial Pacific $\left(10^{\circ} \mathrm{S}-10^{\circ} \mathrm{N}\right)$ & $1960-2014$ \\
ATL & Atlantic $\left(30^{\circ} \mathrm{S}-70^{\circ} \mathrm{N}\right)$ & $1960-2014$ \\
MIROC & & \\
GLOB & Global oceans & $1950-2010$ \\
eqPAC & Equatorial Pacific $\left(10^{\circ} \mathrm{S}-10^{\circ} \mathrm{N}\right)$ & $1950-2010$ \\
ATL & Atlantic $\left(50^{\circ} \mathrm{S}-60^{\circ} \mathrm{N}\right)$ & $1950-2010$ \\
\hline
\end{tabular}

To identify the remote forcing from the equatorial Pacific and Atlantic on the PDO, we further conducted partial ocean assimilation experiments designated the eqPAC and ATL runs, respectively. In these partial assimilation experiments, we use the same model configurations as the GLOB run, except the 3-dimensional observed ocean anomalies are assimilated only in the equatorial Pacific (CESM and MIROC: $\left.10^{\circ} \mathrm{S}-10^{\circ} \mathrm{N}\right)$ and only in the Atlantic (CESM: $30^{\circ} \mathrm{S}$ $-70^{\circ} \mathrm{N}$; MIROC: $50^{\circ} \mathrm{S}-60^{\circ} \mathrm{N}$ ) basins. Each partial assimilation run includes 10 ensemble members with different time ranges for the CESM (1960-2014) and MIROC (1950-2010) after a model spin-up (2 years for the CESM and 5 years for the MIROC). Applications of these partial ocean assimilation experiments and how they affect regional climate are described in previous studies (Chikamoto et al. 2015c; Purich et al. 2016; Chikamoto et al. 2016; Ham et al. 2017; Johnson et al. 2018).

In this study, anomalies are defined as deviations from the climatological mean for 1960-2014 in CESM and for 1950-2010 in MIROC. We chose the climatological mean to cover the entire assimilation period, but consistent results would be obtained if we use the same period of climatology in the CESM and MIROC. To remove the externally forced component due to radiative forcing, we take the difference of ensemble-mean anomalies between the partial assimilation and the historical runs in each model similar to Zhang et al. (2018). A 13-month running mean filter is applied in our analyses to reduce atmospheric stochastic variability for model and observational data. To capture the temporal evolution of observed and model-simulated climate fields, we plot correlation and regression values associated with the PDO index. Given the 13-month running mean in our analysis and the autocorrelation of climate variability, we computed the effective degrees of freedom of the PDO index, which ranges from 12-21 in observations and model experiments (Bretherton et al. 1999). Based on the PDO index, we approximate the effective degrees of freedom to be $\sim 15$ in the following analysis, which corresponds to a statistically significant correlation coefficient of 0.48 at the 95\% significance level. 


\section{Model validation}

To define the PDO index as described in Mantua et al. (1997), we apply an empirical orthogonal function (EOF) analysis to monthly SSTAs in the North Pacific $\left(20^{\circ}\right.$ $-70^{\circ} \mathrm{N}$ ) in observations and the GLOB runs (Fig. 1). Note that the linear trends in each grid point are removed in the observed SSTAs, whereas in the GLOB runs, SSTAs are obtained by subtracting the ensemble mean of the historical run in each model. The leading first EOF modes (EOF1) for the North Pacific SSTAs in GLOB runs capture the observed PDO-like SSTA pattern very well (Fig. 1e and i): the cooler SSTs in the KOE region and its surrounding warmer SSTs along the west coast of North America (Mantua and Hare 2002; Newman et al. 2016). The percentages of explained variance in EOF1 (Fig. 1) are well separated from the second and third modes (HadSST: 16.8\%, 8.5\%, 7.9\%; ERSST: $22.3 \%, 14.9 \%, 8.0 \%$; CESM GLOB: $29.8 \%, 14.7 \%, 7.8 \%$; ProjD: 22.8\%, 13.7\%, 8.4\%; MIROC GLOB: $28.6 \%, 13.9 \%, 6.2 \%$, in first, second, and third modes, respectively). All of the second modes of reanalysis and GLOB runs show a SSTA pattern similar to the North Pacific Gyre Oscillation (NPGO), as described by Di Lorenzo et al. (2008). The GLOB runs of both the CESM and MIROC have comparable variances explained that are larger than the observations, and the monthly principal components are strongly correlated with each other ( $R=0.79$ ) for the time period that overlaps between the two models (1960-2010). Whereas the principal components of EOF1 in observations are almost identical with each other for the 1950-2014 period ( $R>0.97)$, the GLOB runs in CESM and MIROC show slightly lower correlation coefficients with observations $(R=0.88$ and 0.78 for HadSST, $R=0.87$ and 0.81 for ERSSTv4, and $R=0.87$ and 0.74 for ProjD, respectively). Because no atmospheric observations are assimilated into these models, higherfrequency PDO variability is filtered out based on the ensemble mean of 10 members in the GLOB runs. Alternatively, this lower correlation may arise from the linear detrend method to estimate the climate response to radiative forcing in observations. When we apply a 13-month running mean filter to the monthly principal components of EOF1, correlation coefficients of the GLOB runs in the CESM and MIROC with observations increase substantially ( $R=0.93$ and 0.87 in HadSST, $R=0.95$ and 0.85 in ERSSTv4, and $R=0.94$ and 0.81 in ProjD, respectively). Consistent with this EOF analysis, the GLOB runs capture the observed running-mean SSTA variances in the North Pacific well (Fig. 2), although there are some model biases for their patterns (Oshima and Tanimoto 2009). These results support our approach in capturing the interannualto-decadal components of the North Pacific, including the PDO. Hereafter, a 13-month running mean filter is applied to all monthly anomalies, and the PDO index is defined as the 13-month running mean for the principal component of EOF1 (black lines in the right panels of Fig. 1).

To validate the Aleutian low variability in our models, we correlated sea level pressure anomalies (SLPAs) and SSTAs with the observed and GLOB PDO indices in Fig. 3. As pointed out by previous studies (e.g., Newman et al. 2016), we find that the positive phase of the PDO (SST cooling in the KOE region) accompanies the strengthened Aleutian low variability (negative SLPAs in the North Pacific) in all of observations and GLOB runs (Qiu et al. 2007). Consistent with the SLP patterns, the GLOB runs in the CESM and MIROC correlate with the observed SLP variability in the Aleutian low region $\left(30^{\circ} \mathrm{S}-65^{\circ} \mathrm{N}, 160^{\circ} \mathrm{E}-140^{\circ} \mathrm{W} ; R=0.41\right.$ and 0.46 , respectively) otherwise known as the North Pacific Index (Trenberth and Hurrell 1994). In addition to Aleutian low variability, the PDO-like pattern accompanies positive SLPAs over the Indian and Australia region and negative SLPAs over the central and eastern tropical Pacific in the observations and GLOB runs. This zonal SLPA gradient in the Indo-Pacific sector is closely related to El Niño-like SST warming in the tropical Pacific, which is the primary driver of the PDO on interannual timescales through the atmospheric bridge (Alexander et al. 2002, 2010). Even though atmospheric data are not assimilated into the models, the GLOB runs simulated the Aleutian low variability associated with the PDO index quite well, albeit overestimating positive SLPAs in the northwestern subtropical Pacific.

In the Atlantic basin, however, the SSTA and SLPAs associated with the PDO show more diverse patterns among observations and GLOB runs. The observations and CESM GLOB run (Fig. 3a-c, e) show that the PDO index positively correlates with SLPAs in the tropical Atlantic and Indian Oceans, whereas the tropical Atlantic SLPA correlations are unclear in the MIROC GLOB run (Fig. 3d). Moreover, the MIROC GLOB run shows SST warming in the tropical Atlantic associated with a positive PDO-like pattern, which is differentiated from the weak SST cooling in observations and the CESM GLOB run. By examining the ProjD (Fig. 3c), we also note stronger SSTA correlations in the south tropical Atlantic compared to the other observations and GLOB simulations. In the North Atlantic, there are moderate negative SSTA correlations in observations and the CESM GLOB, which accompanies negative SLPA correlations. These discrepancies in the Atlantic may impact the atmospheric bridge given inter-basin impacts to the Pacific. 
(a) HadSST

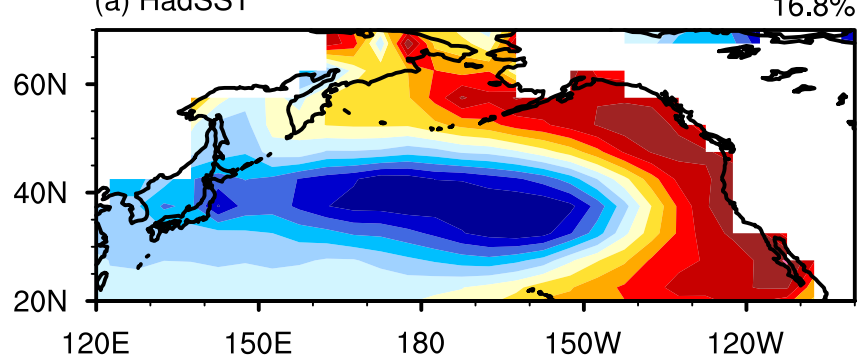

(c) ERSST

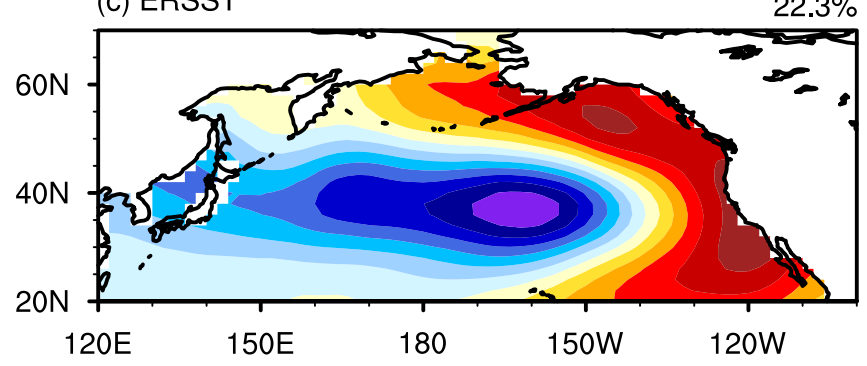

(e) CESM GLOB

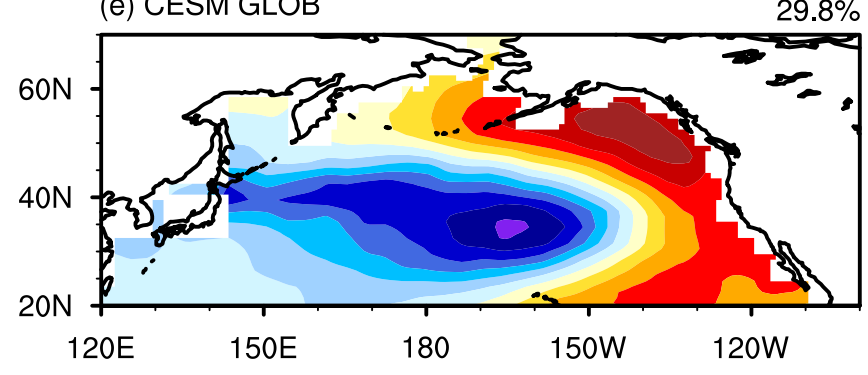

(g) ProjD

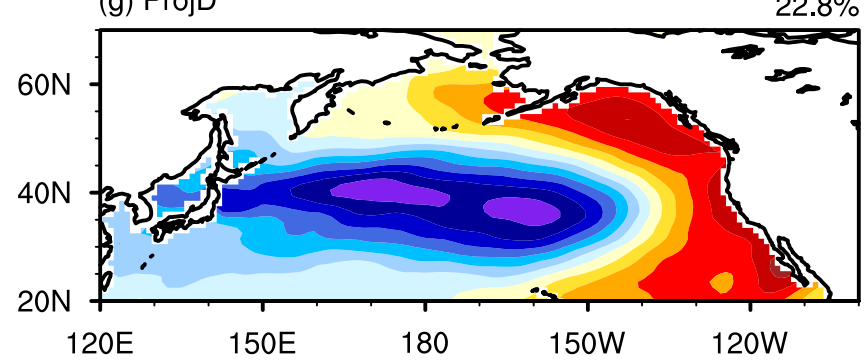

(i) MIROC GLOB
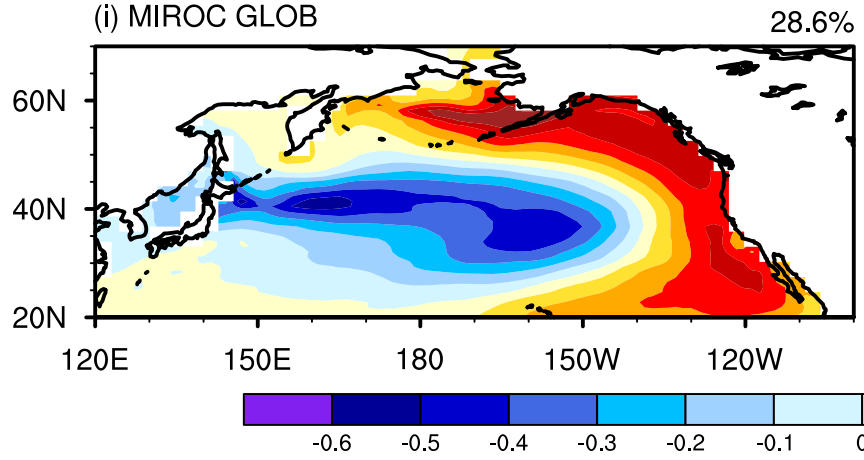

Fig. 1 Regressed SSTA patterns (left panels) and principal components (right panels) associated with the leading EOF mode of monthly SSTAs in the North Pacific based on the (a, b) UK Met Office's HadSST version 3 (1900-2014), (c, d) National Centers for Environmental Prediction's ERSST version 4 (1960-2014), (g, h) Japanese Meteorological Agency ProjD (1950-2010) and the GLOB (b) HadSST

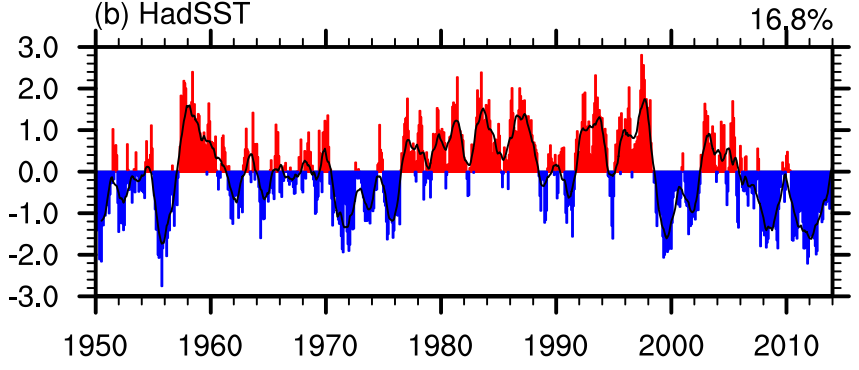

(d) ERSST

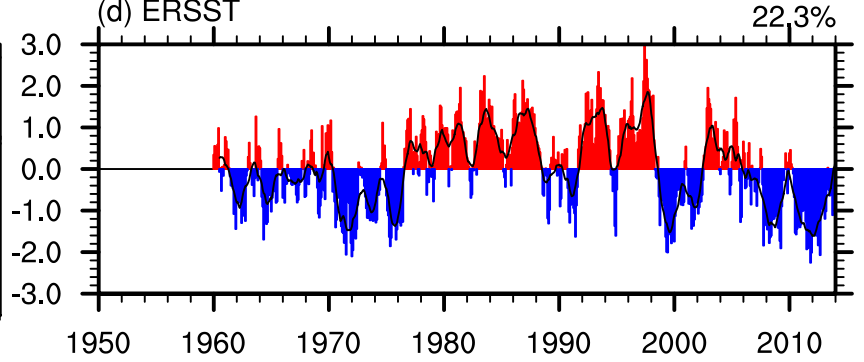

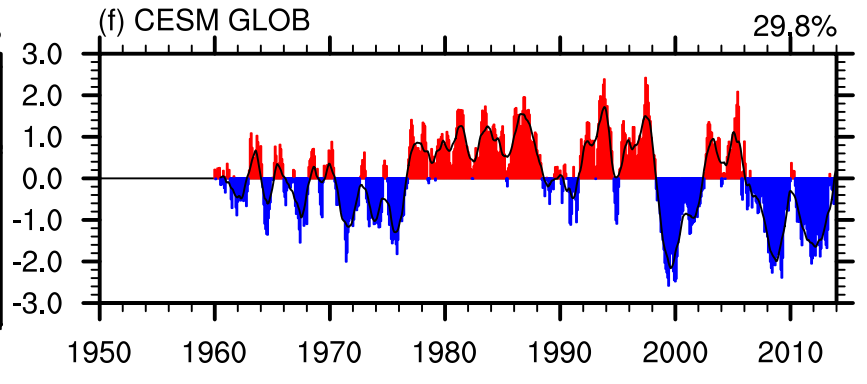
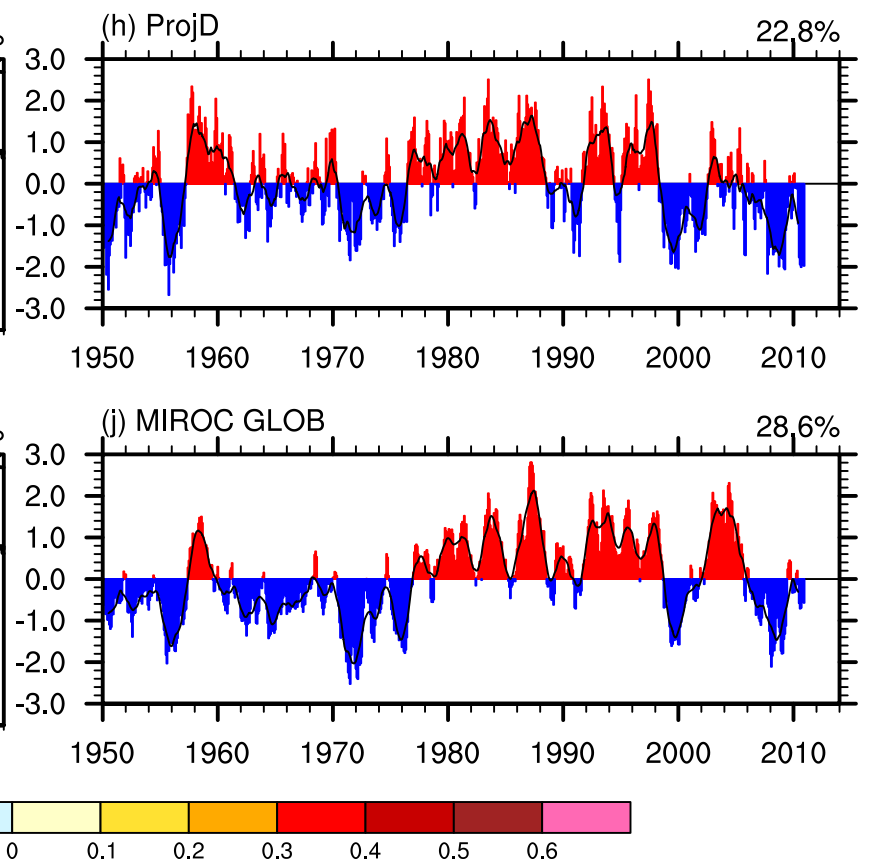

runs of the (e, f) CESM (1960-2014) and (i,j) MIROC (1950-2010). Units in regression plots are ${ }^{\circ} \mathrm{C}$. The variance explained by the first EOF mode is indicated in the upper-right corner of each plot. Positive (negative) values are red (blue). A black line in the right column is a 13-month running average for the principal component, which is defined as the PDO index 


\section{CESM}

\section{(a) ERSST}

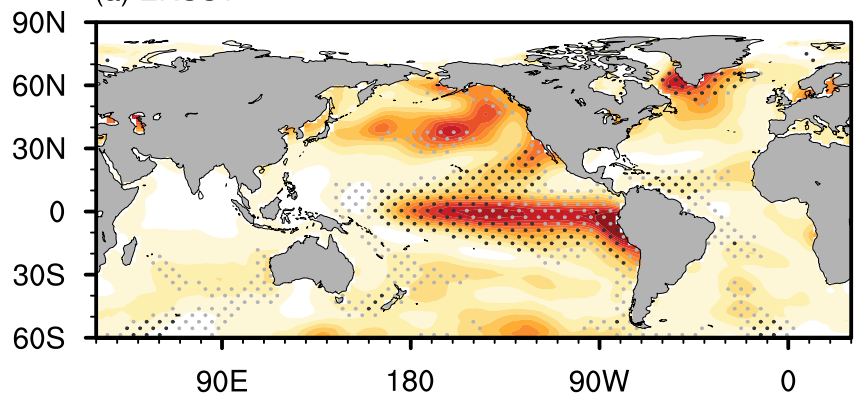

(c) GLOB

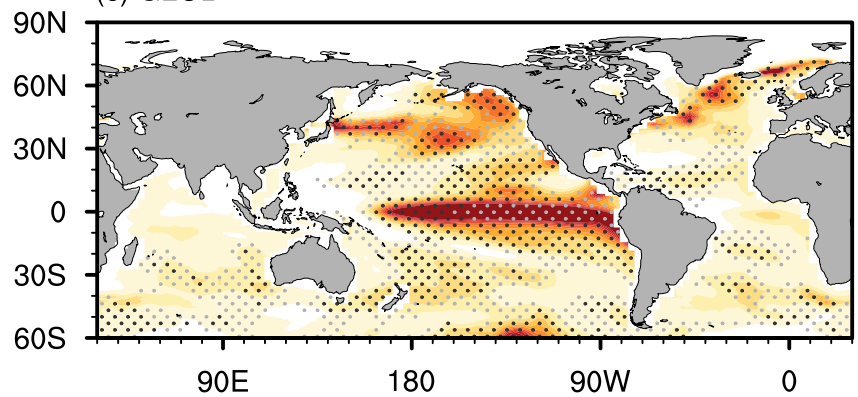

(e) eqPAC

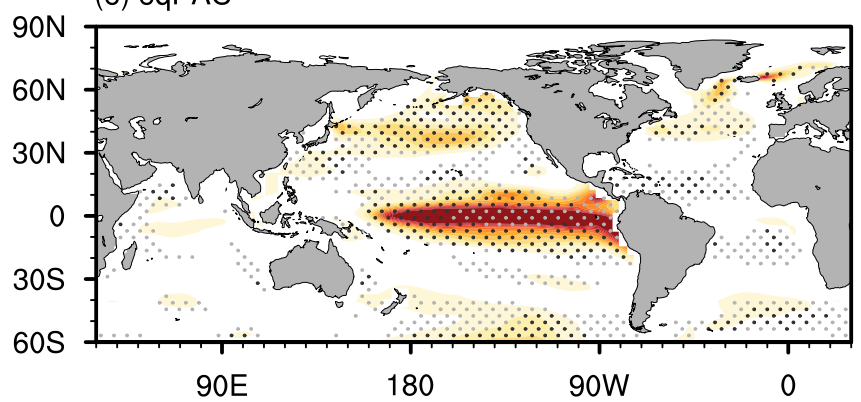

(g) ATL

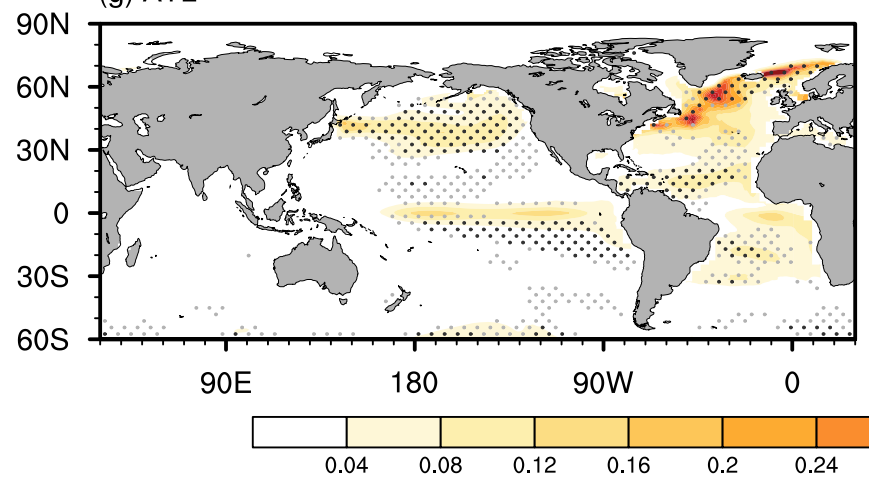

Fig. 2 13-month running mean total SSTA variance (colors) and the ratio of 10-year low-pass filtered SSTA variance to monthly total SSTA variance (stippling) in (a, b) observations, $(\mathbf{c}, \mathbf{d})$ GLOB, $(\mathbf{e}, \mathbf{f})$ eqPAC, and $(\mathbf{g}, \mathbf{h})$ ATL runs in the CESM (left) and MIROC (right).
(b) ProjD

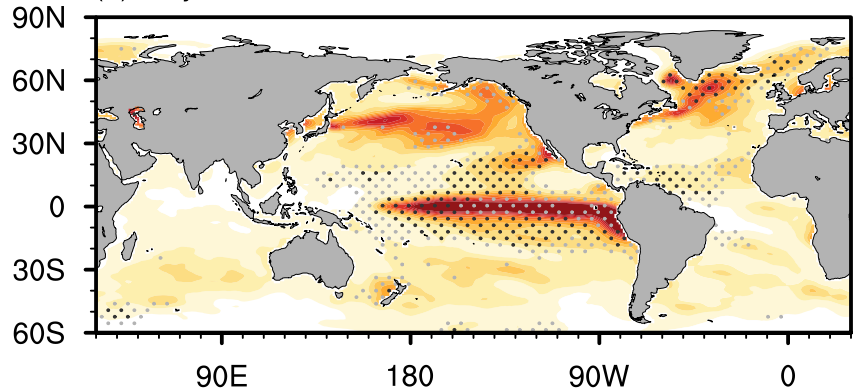

(d) GLOB

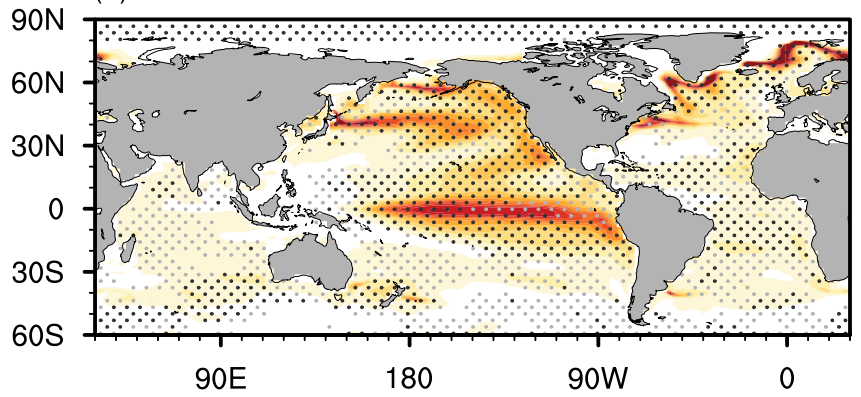

(f) eqPAC

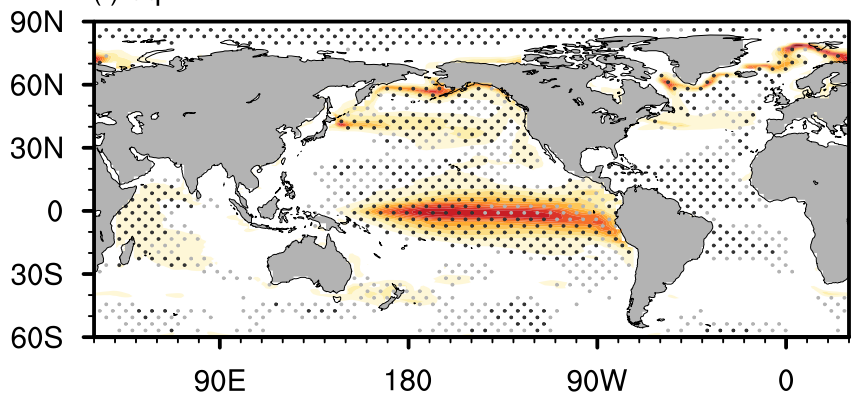

(h) ATL

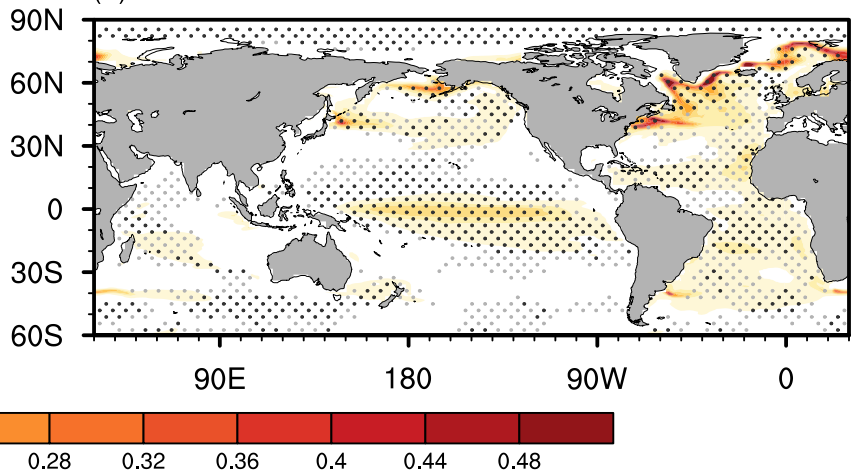

Observations include (a) ERSSTv4 and (b) ProjD. Stippling indicates over $40 \%$ of the variance is in the decadal component, whereas dark grey dots indicate over $50 \%$ of the variance is in the decadal component 
(a) ERSST and JRA55

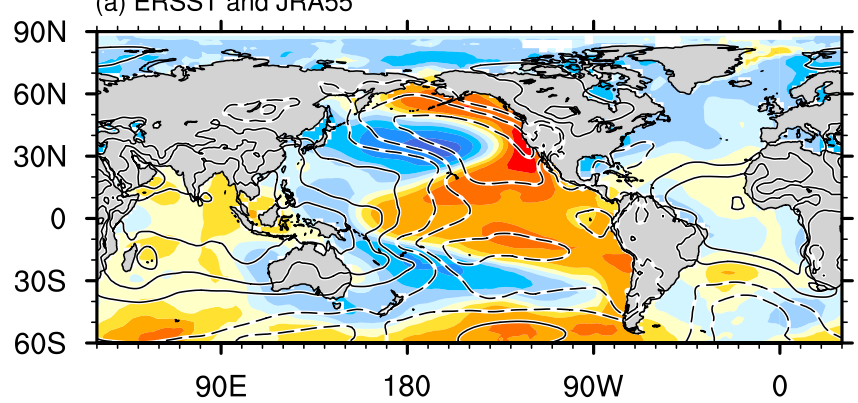

(c) ProjD and NCEP

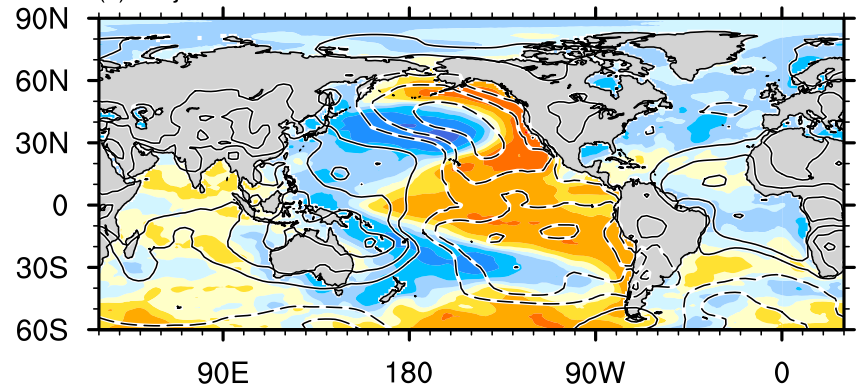

(b) CESM GLOB

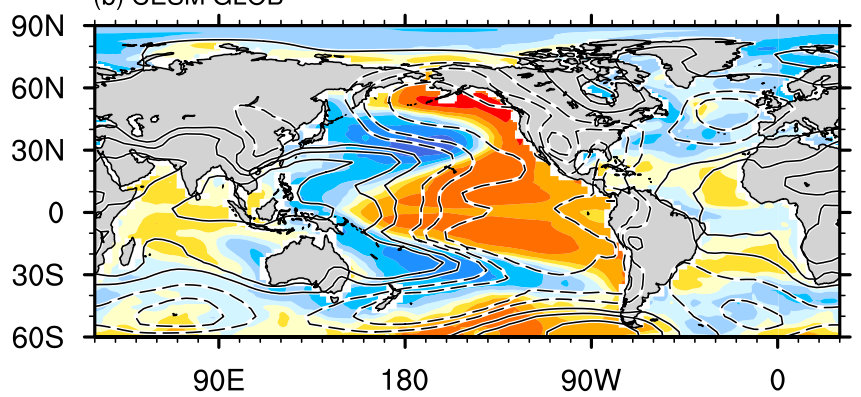

(d) MIROC GLOB

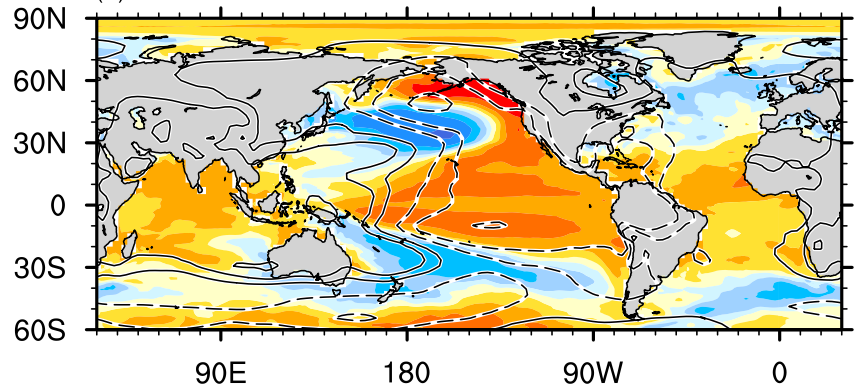

(e) HadSST and HadSLP

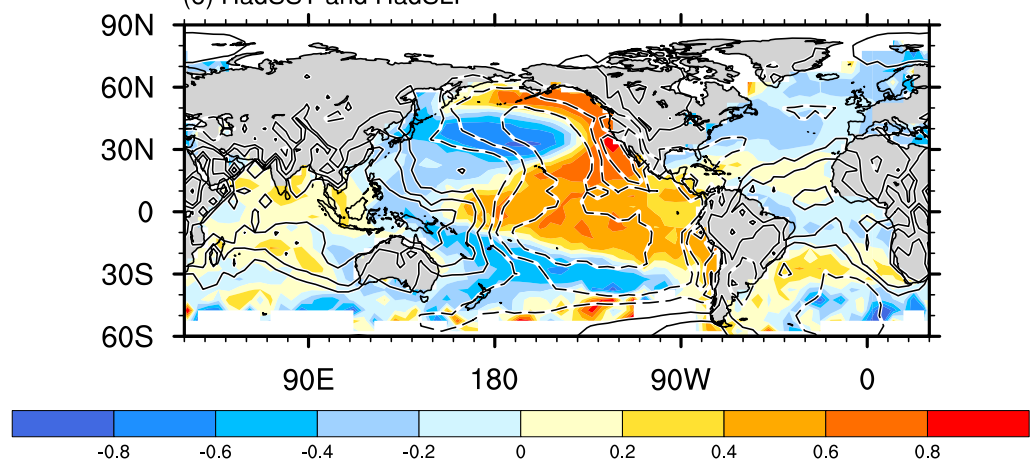

Fig. 3 Correlation maps of SLPAs (contours: solid and broken lines are positive and negative correlations, respectively) and SSTAs (colors) associated with the PDO index in the (a) ERSST and JRA55, (c) ProjD and NCEP, (e) HadSST and HadSLP, and the GLOB runs in the (b) CESM and (d) MIROC. The contour interval is 0.2 with the zero contour omitted

\section{Tropical Pacific origin}

\subsection{Equatorial Pacific impact on PDO}

To identify the tropical Pacific impacts on the PDO, we apply an EOF analysis to the ensemble mean of North Pacific SST variability in the equatorial Pacific (eqPAC) runs (Figs. 4a, b and 5a, b). The leading EOF modes in these eqPAC runs show a PDO-like SST pattern in the North Pacific (Fig. 4), which is consistent with the peaks of total SSTA variance in the North Pacific (Fig. 2e, f). Their variances explained by EOF1 are slightly larger than those in the GLOB runs and observations. The second modes (not shown) in the eqPAC runs depict an NPGO-like feature in the CESM and an unclear SST signal in the MIROC (16.9\% and $8.0 \%$ for the second modes, and $7.3 \%$ and $7.5 \%$ for the third modes in the CESM and MIROC, respectively). The EOF1 principal components in the eqPAC runs also significantly correlate with the GLOB runs ( $R=0.63$ in CESM and 0.66 in MIROC, respectively). Consistent with the idea of the atmospheric bridge proposed by previous studies (Trenberth and Hurrell 1994; Trenberth et al. 1998; Liu and Alexander 2007), in particular, the eqPAC runs capture the positive phase of the PDO during the early 1980s and 1990s, and its negative phase during the mid 1970s and early 2000s.

Associated with the atmospheric bridge, Aleutian low variability is the primary factor in connecting tropical Pacific SST forcing and the PDO-like SST response in the North Pacific. To examine these connections, we produced lead-lag correlations of the PDO index (the first principal components) with Aleutian low variability (SLPA in $30^{\circ} \mathrm{N}-65^{\circ} \mathrm{N}, 160^{\circ} \mathrm{E}-140^{\circ} \mathrm{W}$ ) 


\section{CESM}

(a) eqPAC
$39.4 \%$

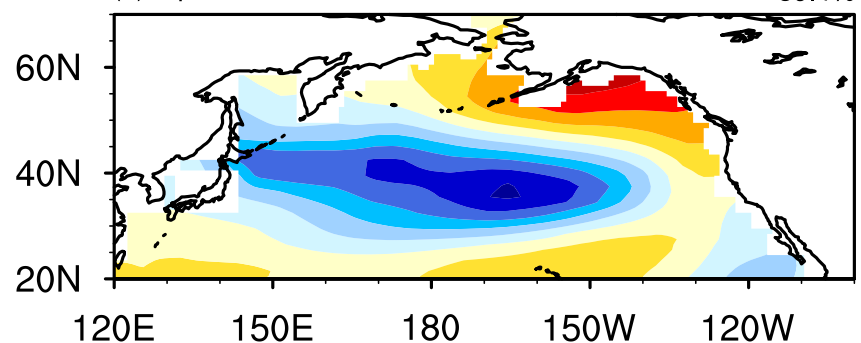

(c) ATL

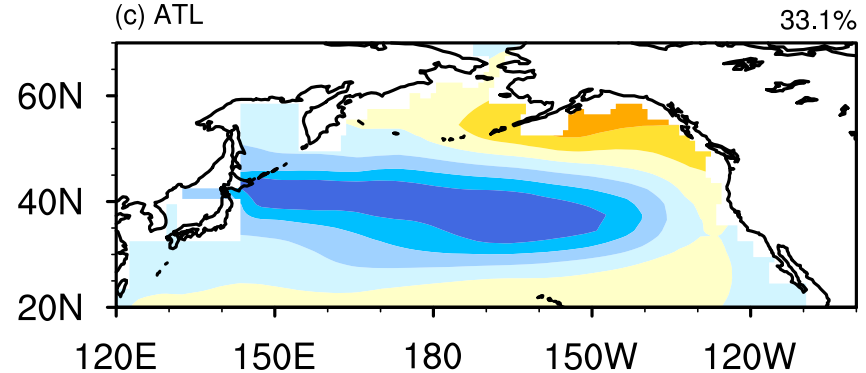

(b) eqPAC

MIROC

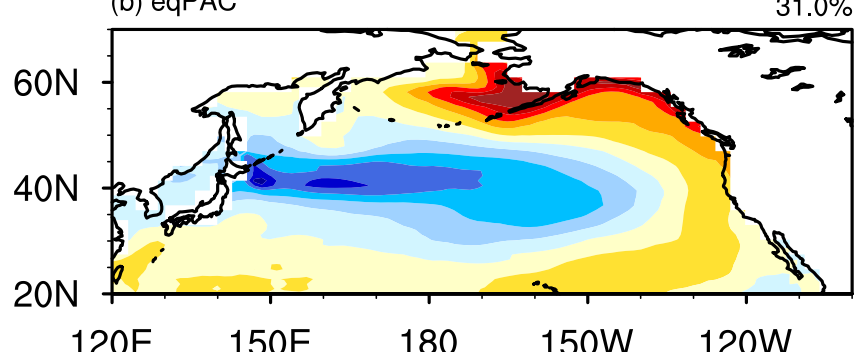

(d) ATL

$8.6 \%$
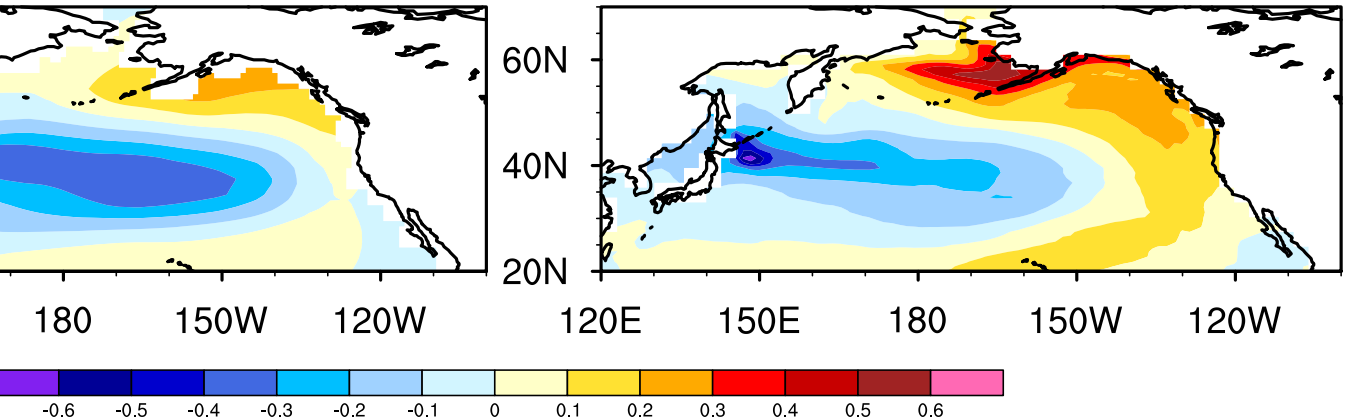

Fig. 4 Regressed SSTA patterns (left panels) associated with the leading EOF mode of monthly SSTAs in the North Pacific $\left(20^{\circ}-\right.$ $\left.70^{\circ} \mathrm{N}\right)$ in $(\mathbf{a}, \mathbf{b})$ the eqPAC and $(\mathbf{c}, \mathbf{d})$ ATL runs during 1960-2014 for the CESM (left panels) and 1950-2010 for the MIROC (right panels).
Units are in ${ }^{\circ} \mathrm{C}$. Note that the color scale is the same as Fig. 1. The variance explained by EOF1 in each run is denoted on the top right corner of each sub-panel
CESM
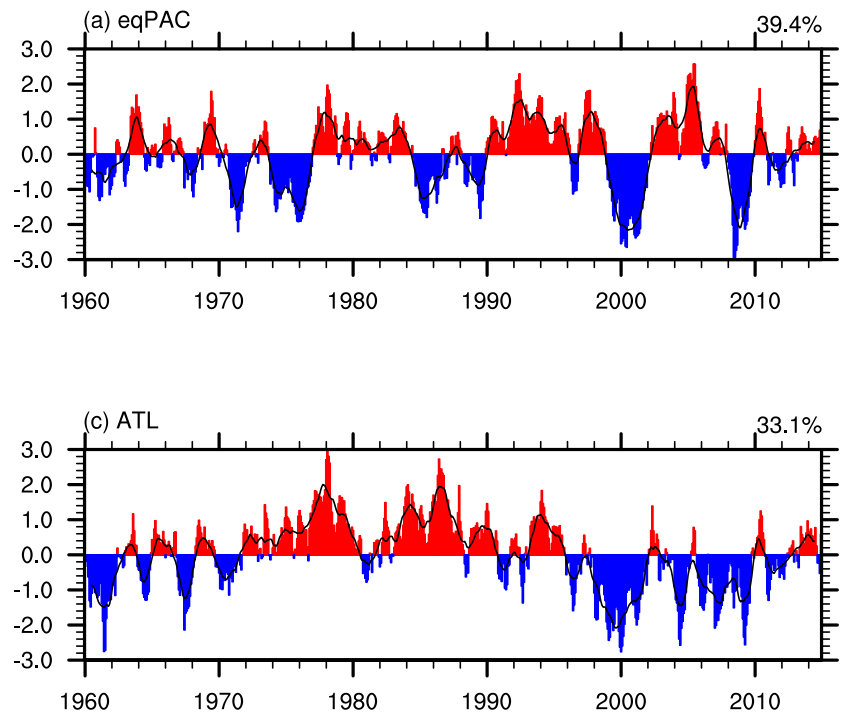

Fig. 5 Principal components associated with the leading EOF mode of monthly North Pacific SSTAs $\left(20^{\circ}-70^{\circ} \mathrm{N}\right)$ in $(\mathbf{a}, \mathbf{b})$ the eqPAC and (c, d) ATL runs during 1960-2014 for the CESM (left) and 1950-

and the Niño 3.4 index (SSTAs in $5^{\circ} \mathrm{S}-5^{\circ} \mathrm{N}, 170^{\circ} \mathrm{W}-120^{\circ} \mathrm{W}$ ) in the GLOB and eqPAC runs (black and blue lines in Fig. 6).

\section{MIROC}
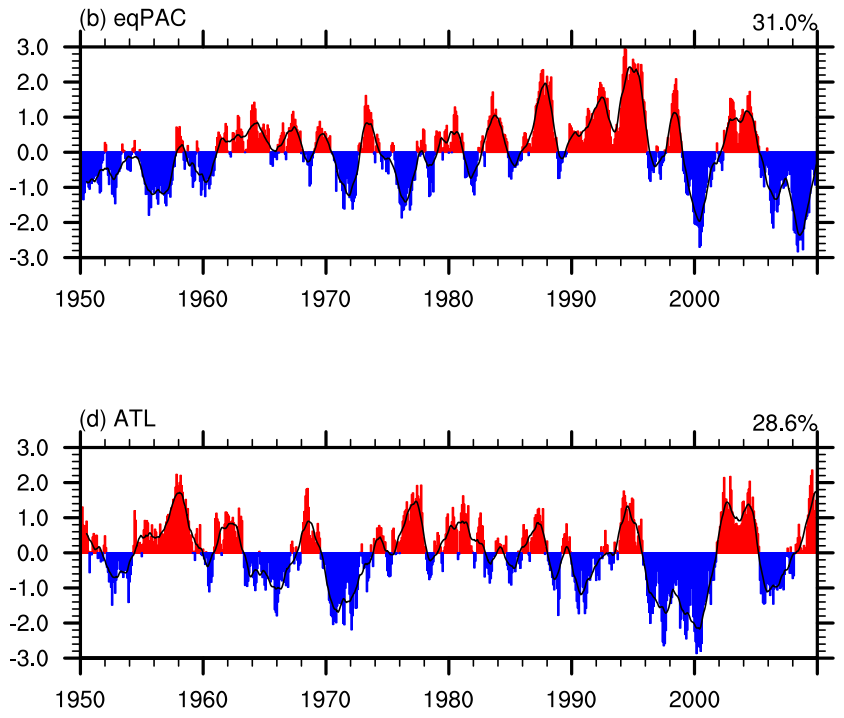

2010 for the MIROC (right panels). The variance explained by the first EOF mode in each run is denoted on the top right corner of each sub-panel

The eqPAC runs show that Aleutian low variability negatively correlates with the PDO index (Fig. 6a, b), with the strongest 


\section{CESM}

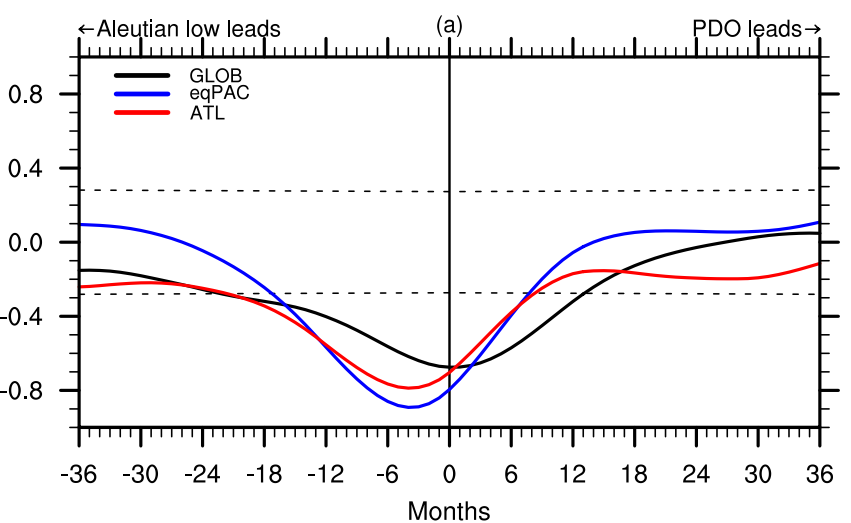

MIROC

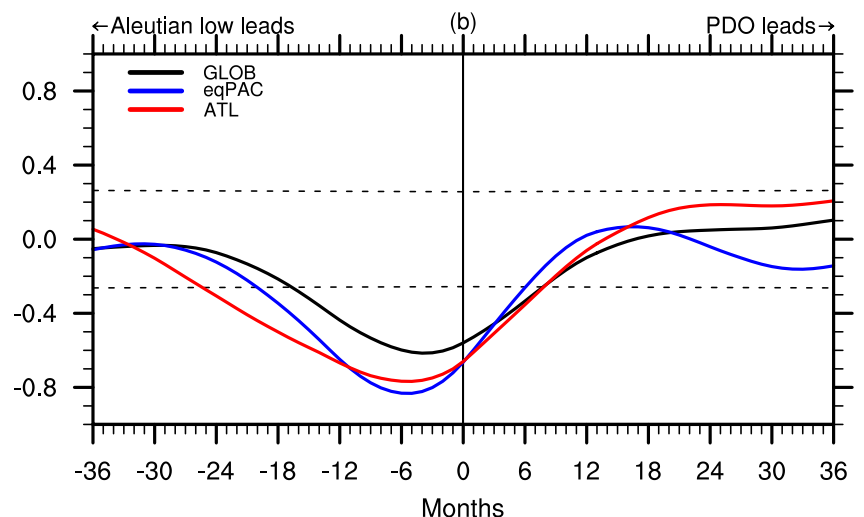

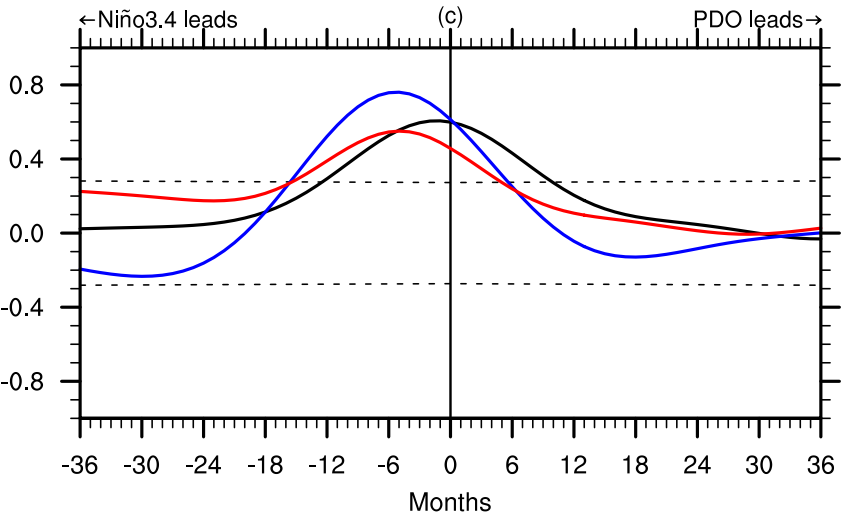

Fig. 6 Lead-lag correlations between $(\mathbf{a}, \mathbf{b})$ the PDO and Aleutian low indices and $(\mathbf{c}, \mathbf{d})$ the PDO and Niño 3.4 indices for the GLOB (black), eqPAC (blue), and ATL (red) runs in (left) the CESM and (right) MIROC. Negative lag months indicate that $(\mathbf{a}, \mathbf{b})$ the NPI leads the PDO and (c, d) the Niño 3.4 index leads the PDO, whereas

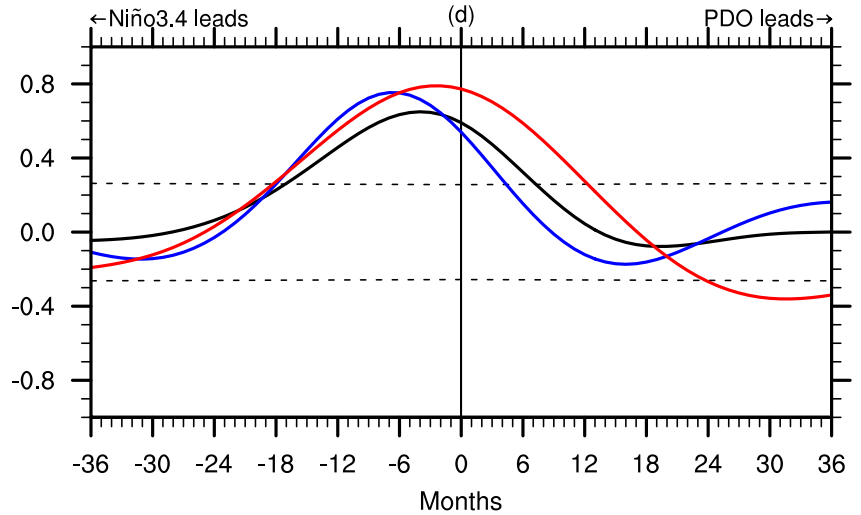

the positive lag months indicate the opposite. The $\mathrm{Y}$ axis indicates correlation coefficients, and the $\mathrm{X}$-axis shows months. A horizontal dashed line indicates a statistical significance at the $95 \%$ confidence level using the two-sided Student's t-test

Pacific SST warming enhances local precipitation, which causes the Matsuno-Gill type atmospheric response (Taschetto et al. 2010); this is shown in a quadrupole structure of upper-tropospheric streamfunctions over the tropical Indo-Pacific sectors (Fig. 8a, b). Consistent with the atmospheric bridge process (Trenberth et al. 1998), this tropical Pacific SST warming drives the PNA-like wave train pattern in the upper-troposphere and its associated wave-activity flux (arrows): positive streamfunction anomalies at $250 \mathrm{hPa}$ (corresponding to the higher pressure) with the PDO over the northern tropical Pacific and alternating lower and higher pressure centers in the North Pacific and North American regions, respectively (Fig. 8a, b). In particular, the uppertropospheric low pressure center in the North Pacific consists of an equivalent barotropic structure and affects Aleutian low variability (Yu and Zwiers 2007). Our eqPAC runs clearly demonstrate that tropical Pacific climate variability is the main driver for the PDO-like SST response with strong agreement between the CESM and MIROC, a feature that also lends credibility to our partial assimilation experiments. 


\section{CESM}

(a) ERSST and JRA55

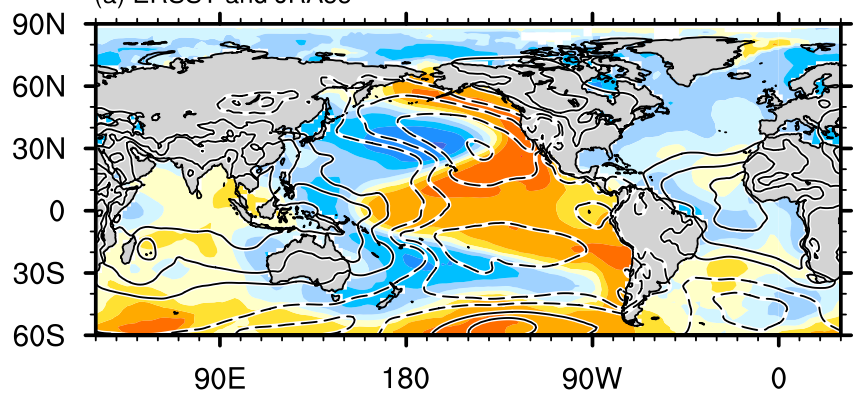

(c) GLOB

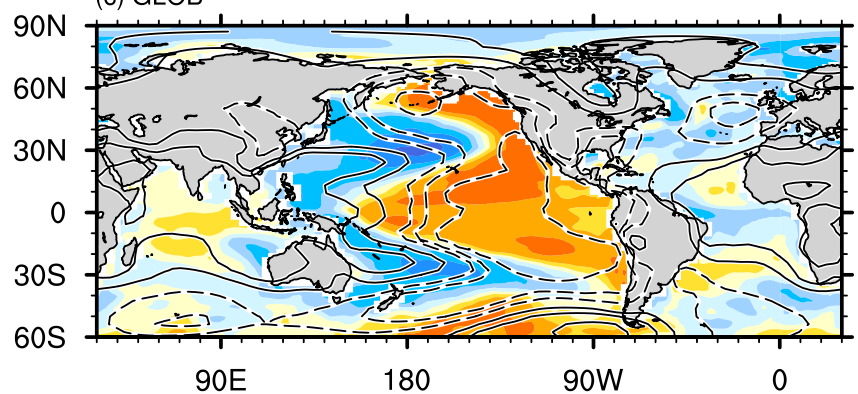

(e) eqPAC

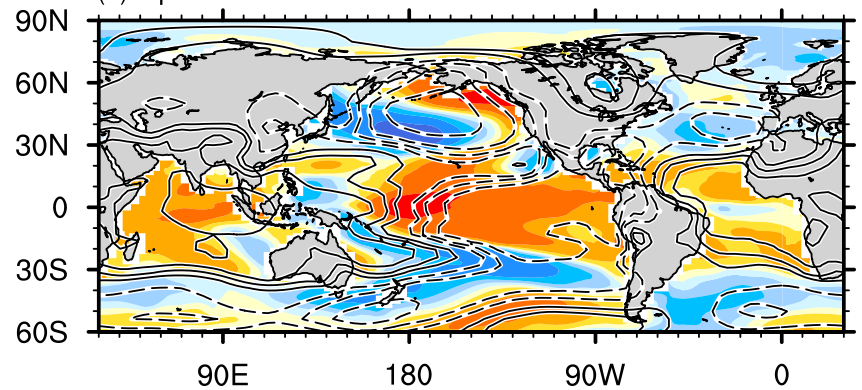

(g) ATL

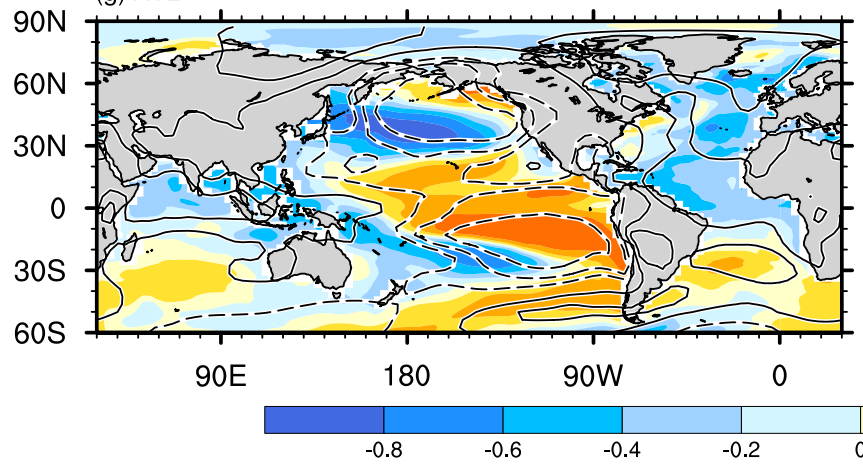

Fig. 7 Correlation maps of SLPAs (contours: solid and broken lines are positive and negative correlations, respectively) and SSTAs (colors) at 5 months lead associated with the PDO index in $(\mathbf{a}, \mathbf{b})$ observations, (c, d) GLOB, (e, f) eqPAC, and $(\mathbf{g}, \mathbf{h})$ ATL runs in the (b) ProjD and NCEP

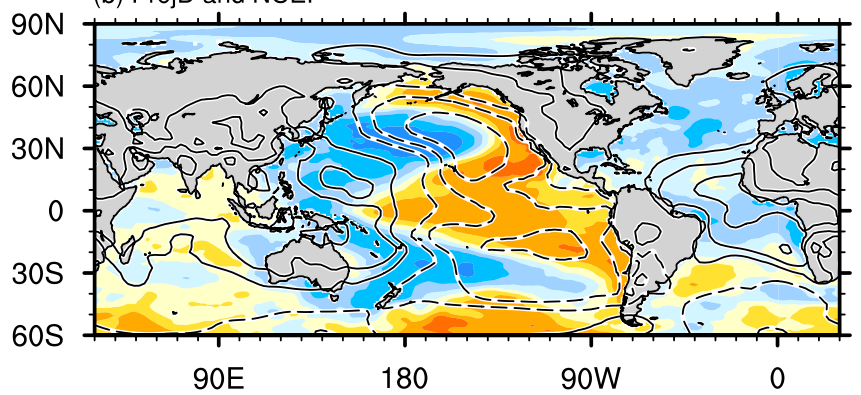

(d) GLOB

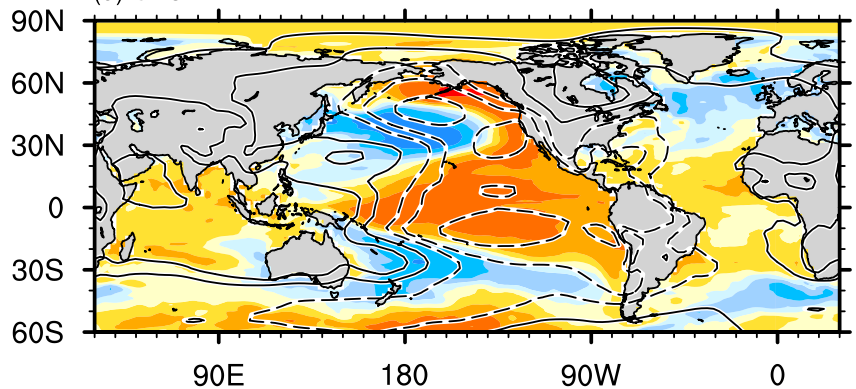

(f) eqPAC

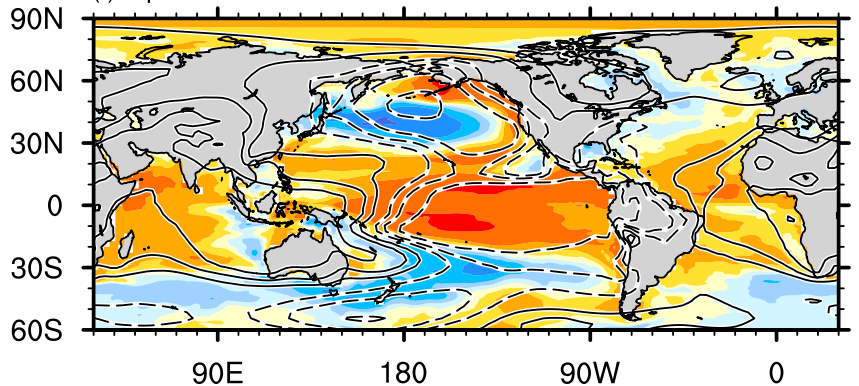

(h) ATL

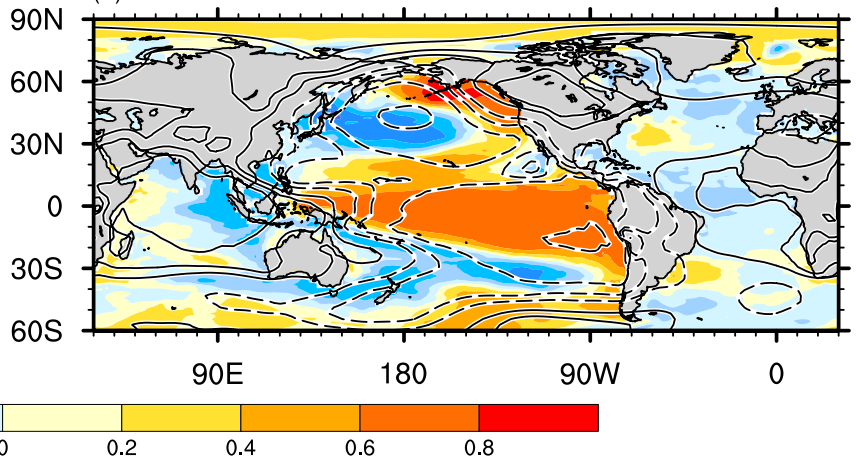

CESM (left) and MIROC (right). Observations include (a) ERSSTv4 and JRA55 and (b) ProjD and NCEP. The contour interval is 0.2 with the zero contour omitted, whereas SSTAs are in ${ }^{\circ} \mathrm{C}$. A 13-month running mean filter is applied to all anomalies 
CESM

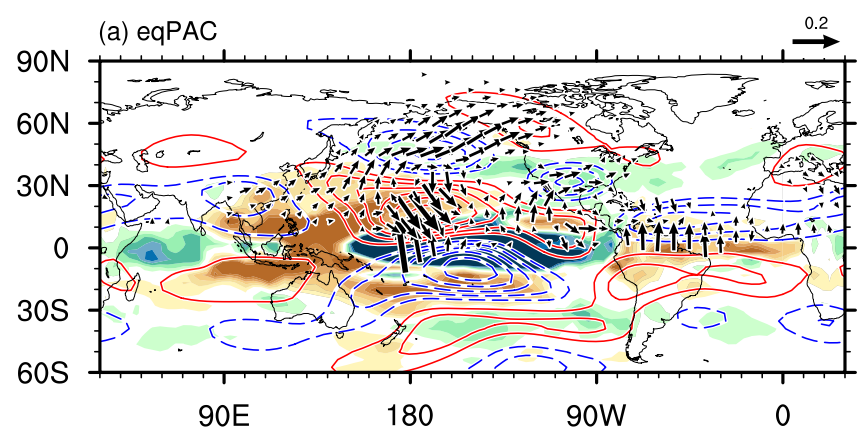

(c) ATL

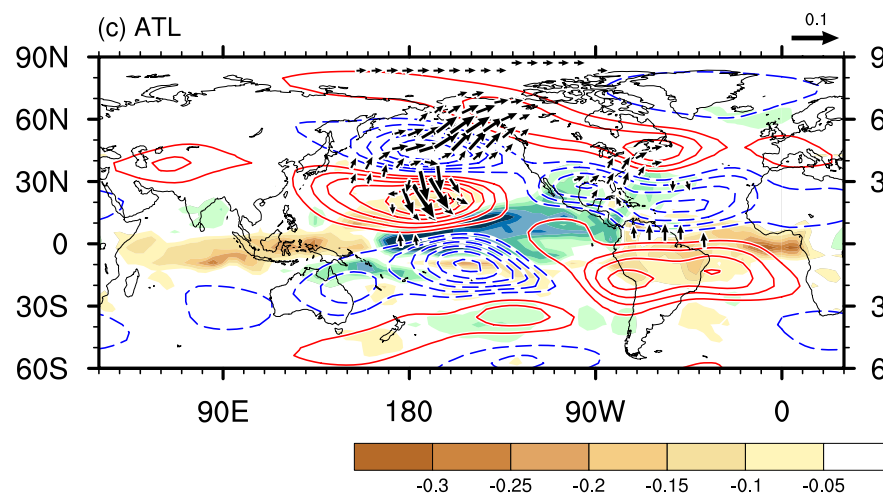

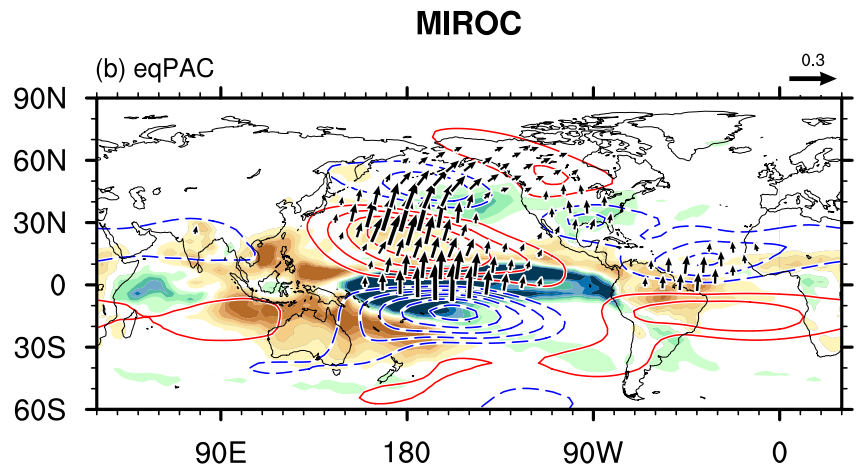

(d) ATL

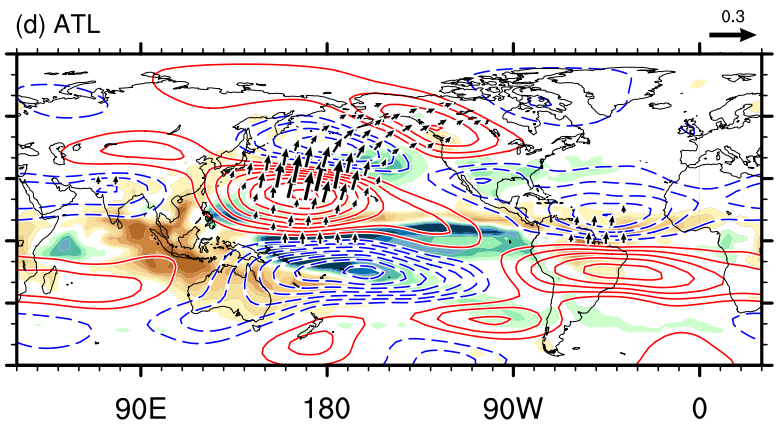

Fig. 8 Regression maps of streamfunction (solid and broken contours correspond to positive and negative anomalies, respectively) and precipitation anomalies (shaded) at 5 months lead time associated with the PDO index in $(\mathbf{a}, \mathbf{b})$ the eqPAC and $(\mathbf{c}, \mathbf{d})$ ATL runs in the CESM (left) and MIROC (right). Only regressed precipitation anomalies that have a corresponding correlation coefficient stronger than 0.25 are plotted. Precipitation has units in $\mathrm{mm} \mathrm{day}^{-1}$. The zonal mean was removed from the streamfunction anomaly (contour interval: $0.4 \times 10^{6} \mathrm{~m}^{2} \mathrm{~s}^{-1}$ in the eqPAC runs and $0.2 \times 10^{6} \mathrm{~m}^{2} \mathrm{~s}^{-1}$ in the ATL

\subsection{Equatorial Pacific impact on Atlantic}

In the eqPAC runs, we see correlations of SSTAs and SLPAs over the tropical Atlantic with the PDO index (Fig. 7e and f), suggesting an equatorial Pacific impact on the tropical Atlantic basin. According to the previous studies (Chiang and Sobel 2002; Sobel et al. 2002; Chiang and Lintner 2005; Chikamoto and Tanimoto 2005; Chang et al. 2006), El Niño events lead tropospheric warming in the entire tropics due to atmospheric Kelvinwave propagation, which then induces SST warming in the tropical Atlantic and Indian Oceans through humidity-driven latent heat fluxes (called the TT-mechanism, where TT designates tropical tropospheric temperature). El Niño also induces SST warming in the northern tropical Atlantic through the PNA-like wave propagation from the Pacific to the North Atlantic (Wallace and Gutzler 1981; Cai et al. 2019). Consistent with these mechanisms, the eqPAC runs (Fig. 7e, f) clearly demonstrate that the El Niño-like SST warming in the equatorial Pacific induces runs). Positive (negative) streamfunction anomalies indicate a clockwise (anti-clockwise) circulation. Vectors represent wave-activity flux (units: $\mathrm{m}^{2} \mathrm{~s}^{-2}$ ) calculated from streamfunctions at $250 \mathrm{hPa}$ regressed on the PDO index (Takaya and Nakamura 2001). Note that waveactivity vectors are displayed only in the northern hemisphere. Reference vectors are denoted in the upper right-hand corner of each plot. Wave-activity fluxes exceeding 0.02 and $0.05 \mathrm{~m}^{2} \mathrm{~s}^{-2}$ are plotted in the CESM and MIROC, respectively

higher SLPs in the tropical Atlantic and Indian Oceans and a subsequent ocean response as seen in the SST warming in those oceans.

In observations, by contrast, we find tropical Atlantic SST cooling associated with the PDO index despite higher SLPs at the same location (Fig. 7a, b). Because SST cooling contributes to locally higher SLPs, the higher observed SLPs in the tropical Atlantic associated with the PDO index are mainly driven by the local SST cooling rather than the remote impact from the equatorial Pacific. In other words, our results suggest that the SLP variability in the tropical Atlantic has two components: a remotely forced component from the equatorial Pacific and a locally driven component within the tropical Atlantic. Whereas the former leads the same phases of SSTAs in the tropical Pacific and Atlantic, the latter has the potential to induce the opposite phases of SSTAs between the tropical Pacific and Atlantic, as seen in the observations and CESM GLOB run (Fig. 7a-c). The discrepancy of tropical Atlantic SSTAs between observation and eqPAC runs suggest 
that the Atlantic has its own variability independent from the tropical Pacific, which opens up the possibility of the Atlantic impact on the PDO.

\section{Atlantic impacts on the PDO}

To identify the Atlantic impacts on PDO, we apply an EOF analysis of the ensemble mean of North Pacific SST variability in the Atlantic (ATL) partial assimilation runs (bottom panels in Figs. 4 and 5). These first EOF modes explain about $30 \%$ of total variance, which are well separated from the second and third modes (CESM: $33.1 \%$, $18.9 \%, 7.7 \%$; MIROC: $28.6 \%, 9.1 \%, 7.2 \%$ of explained variances for the first, second, and third modes). The first modes in the ATL runs also positively correlate with the first modes in the GLOB runs ( $R=0.54$ in the CESM and 0.35 in the MIROC, respectively). By contrast to the first EOF modes, the second and third EOF modes in the ATL runs show much weaker correlations with the first EOF modes in the GLOB runs $(R=0.23$ and 0.24 in the second and third modes of the CESM ATL run; $R=0.06$ and 0.14 in the MIROC ATL run). Results of these correlation coefficients suggest that in the ATL runs, the PDO-like SST pattern is the most dominant mode of North Pacific SST variability, albeit the simulated spatial pattern of the PDO in the ATL runs are slightly different with observations in terms of the meridional position of negative SSTAs. Another interesting feature in the ATL runs is that there are weak and insignificant correlations of the first principal components between the ATL and eqPAC runs ( $R=0.26$ in the CESM and 0.20 in the MIROC, respectively). Higher ATL correlations with the GLOB runs rather than the eqPAC runs supports our hypothesis that the Atlantic Ocean variability can trigger the PDO-like SST pattern. In the ATL runs, we can find negative SSTAs in the tropical Atlantic and Indian Oceans in both the CESM and MIROC (Fig. $7 \mathrm{~g}, \mathrm{~h}$ ), which is differentiated from the eqPAC runs (Fig. 7e, f). This sharp SSTA contrast suggests that interbasin climate interactions originating from the Atlantic Ocean also induces the PDO-like SST response. It is noteworthy that in the ATL runs, the SST warming in the equatorial Pacific is stronger in the MIROC than the CESM, whereas the CESM shows AMO-like SST cooling in the North Atlantic more clearly than the MIROC. Additionally, in the ATL runs, both models show pronounced SSTA variance in the North Pacific, but the CESM has more dominant decadal components compared to the MIROC (dotted region in Fig. 2g, h). These different characteristics between the CESM and MIROC ATL runs imply two inter-related pathways from the Atlantic to the Pacific, as described in the following subsections.

\subsection{Equatorial pathway}

According to previous studies (e.g., Rodríguez-Fonseca et al. 2009; Chikamoto et al. 2012; Ding et al. 2012; McGregor et al. 2014; Chikamoto et al. 2015b; Kucharski et al. 2016; Li et al. 2015; Ruprich-Robert et al. 2017; Cai et al. 2019), Atlantic SST variability modifies tropical inter-basin climate interactions between the Pacific and Atlantic Oceans through the reorganization of the global Walker circulation. Consistent with this idea, we can find cooler SST and higher SLP in the tropical Atlantic and warmer SST and lower SLP in the tropical Pacific in both CESM and MIROC ATL runs (Fig. $7 \mathrm{~g}, \mathrm{~h}$ ). These SSTA/SLPA contrasts between the Pacific and Atlantic accompany less precipitation in the eastern tropical Pacific but more precipitation in the central tropical Pacific (Fig. 8c, d), suggesting the reorganization of the global Walker circulation. As shown by Hovmöller diagrams (Fig. 9) of SST, SLP, precipitation, and upper-tropospheric zonal wind anomalies at the equator $\left(5^{\circ} \mathrm{S}-5^{\circ} \mathrm{N}\right)$ associated with the PDO indices in the ATL runs, SSTA and SLPA contrasts between the Pacific and Atlantic involve uppertropospheric westerly anomalies over the eastern Pacific and Atlantic and easterly anomalies over the western and central Pacific (Fig. 9b, d). The zonal wind anomalies at $850 \mathrm{hPa}$ show a similar pattern but opposite phase as U250. These features highlight the equatorial pathway of inter-basin effects from the Atlantic to the tropical Pacific.

This reorganization of the global Walker circulation through the equatorial pathway is more prominent in the MIROC ATL run compared to the CESM ATL run. In the MIROC ATL run (Fig. 9a), we see SST cooling in the equatorial Atlantic that begins about 36 months before the mature stage of the PDO. This Atlantic SST cooling accompanies locally higher SLP and then its eastward propagation from the Atlantic to the Indian Ocean. The SST cooling and higher SLPs cause decreases in precipitation over the Atlantic-Indian region (Fig. 9a, b) and its compensating atmospheric dynamical response in the equatorial Pacific, as seen in warmer SSTs, lower SLPs, and more precipitation. These atmospheric changes imply that the Atlantic SST forcing triggers strong atmosphere-ocean interactions in the equatorial Pacific through the Bjerknes feedback. The resultant precipitation changes in the equatorial Pacific lead to the Matsuno-Gill type atmospheric response as seen in the equatorial anti-symmetric structure of the upper-tropospheric streamfunction anomalies over the tropical Pacific (Fig. 8d), which induces PNA-like Rossby-wave propagation (arrows) and a PDO-like atmosphere-ocean response in the North Pacific.

In the CESM ATL run, however, equatorial Pacific SST and SLP responses to the Atlantic forcing are much weaker and have shorter timescales compared to the MIROC ATL run (Figs. $7 \mathrm{~g}$ and $9 \mathrm{c}$ ). For example, we can find the CESM 
(a) MIROC - SST (colors) \& SLP (contours)

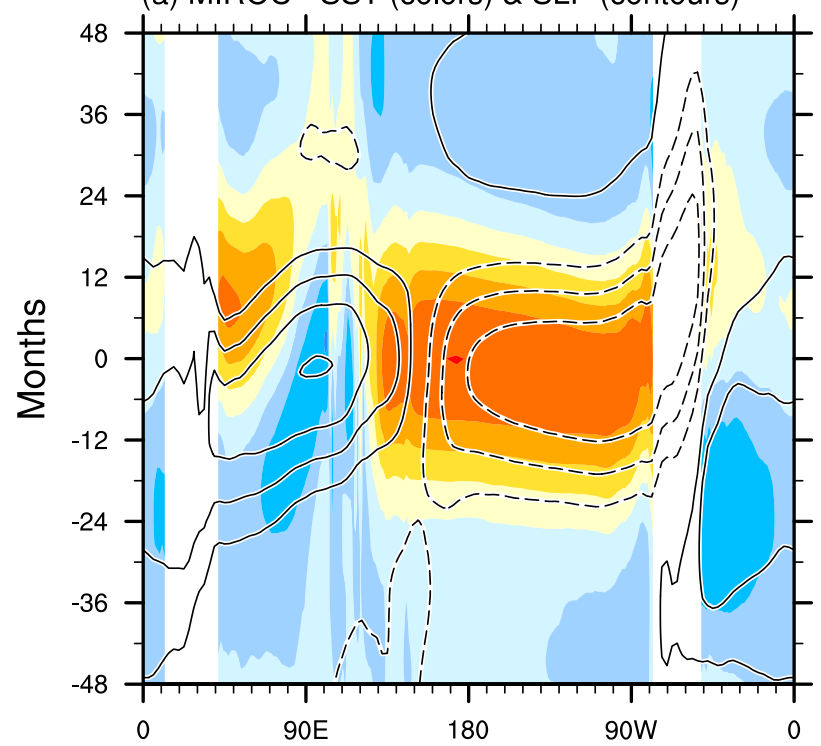

(c) CESM - SST (colors) \& SLP (contour)

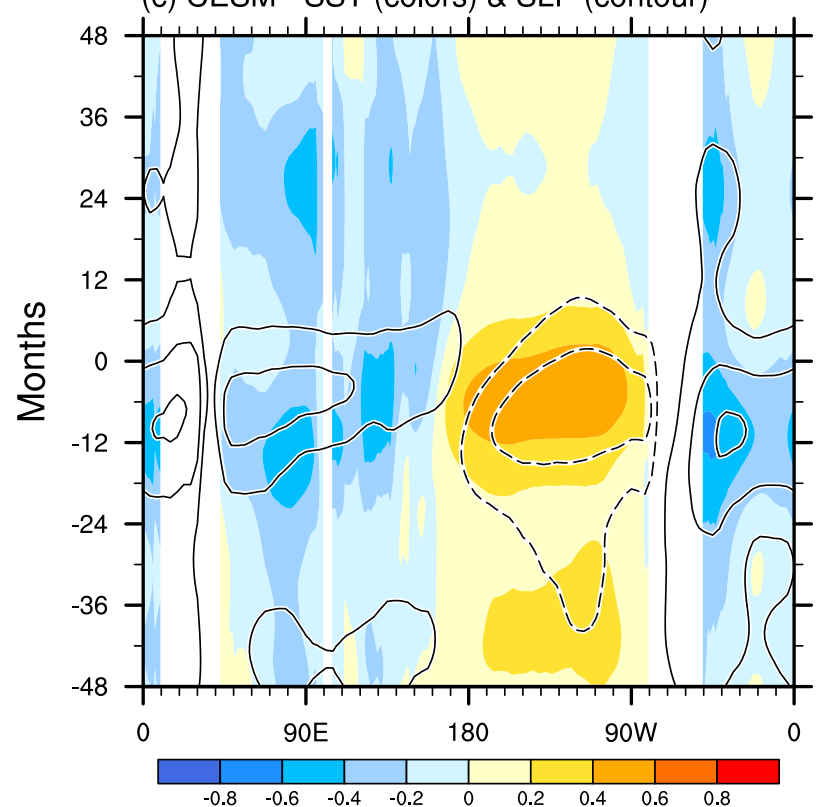

Fig. 9 Hovmöller diagrams for the lead-lag correlation of (a, c) SLP (contours), SST (colors), (b, d) $250 \mathrm{hPa}$ zonal wind (contours), and precipitation anomalies (colors) averaged over the $5^{\circ} \mathrm{S}-5^{\circ} \mathrm{N}$ latitude band with the PDO index in the MIROC (top) and CESM (bottom)

ATL run shows local peaks of Atlantic SSTA and SLPAs 6-18 months before the mature stage of PDO (Fig. 9c), which is a shorter time-lag compared to the MIROC ATL run that has a 36 month lag. These Atlantic anomalies accompany immediate but weaker responses of equatorial Pacific SSTA and SLPAs (Fig. 9c), suggesting weaker Bjerknes activation. In addition to the equatorial Pacific responses, we find totally opposite phases of upper-tropospheric zonal wind anomalies over the Indian Ocean (b) MIROC - Precip (colors) \& U250 (contours)

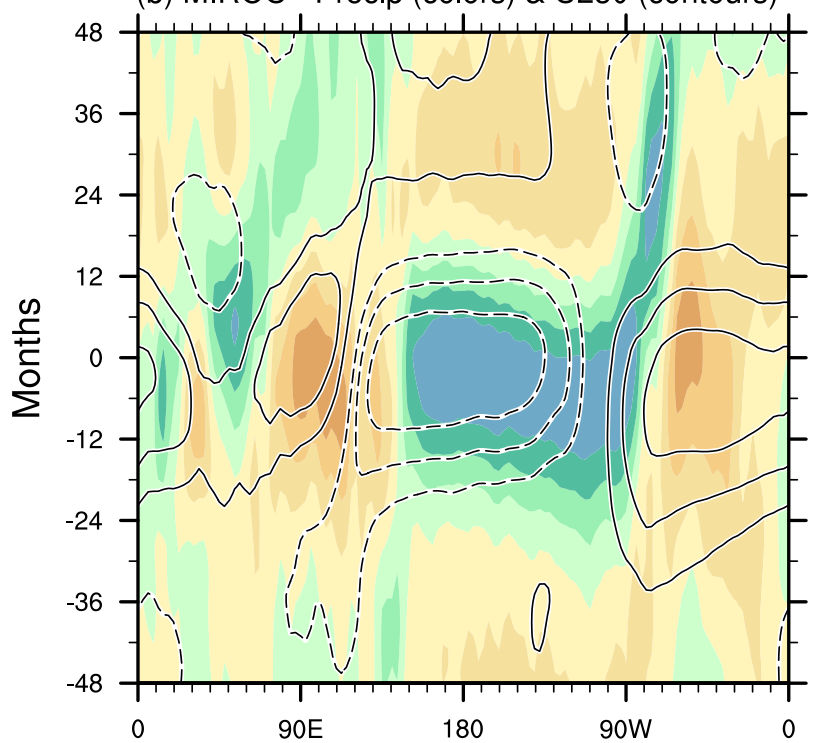

(d) CESM - Precip (colors) \& U250 (contours)

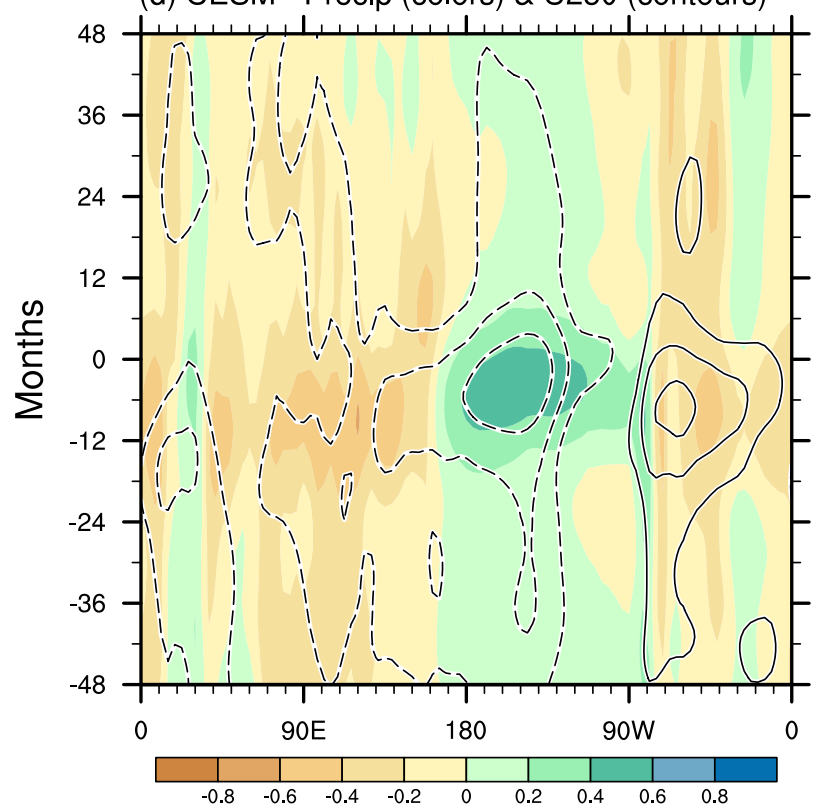

ATL runs. Contour interval is 0.2 with the zero contour omitted. Solid and broken contours are positive and negative correlations, respectively. A 13-month running mean filter is applied to all anomalies

among the MIROC and CESM ATL runs (Fig. 9b, d). Because of this weaker equatorial Pacific response, the upper-tropospheric streamfunction anomalies are unclear over the Indian Ocean in the CESM ATL run (Fig. 8c), compared to the quadrupole structure in the MIROC ATL run (Fig. 8d). Nevertheless, the PDO index in the CESM ATL run is strongly correlated with CESM GLOB run and displays a multidecadal timescale (Fig. 5c). These CESM results suggest that, in addition to the equatorial pathway, 
there is another pathway to explain the Atlantic influence on the North Pacific.

\subsection{North tropical pathway}

As described in the previous section, the PDO index in the CESM ATL run has multi-decadal components with negative phases during the 1960s and 2000s but positive phases during the 1970s and 1980s (Fig. 5c), which reminds us of the temporal variations of the AMO (Trenberth and Shea 2006; Knight et al. 2005). In fact, we can find significant instantaneous correlations between the PDO index in the CESM ATL run and the AMO index in observations $(R=-0.60)$, but even stronger if there is a 7-9 month lag $(R=-0.67)$. Previous literature also pointed out that the PDO is modulated by the remote impact of the AMO (Zhang and Delworth 2007; Okumura et al. 2009; Wu et al. 2011; Kucharski et al. 2016; Sun et al. 2017; Gong et al. 2020). In addition to the multi-decadal timescales, the CESM ATL run shows AMO-like SST cooling in the North Atlantic associated with the positive PDO index (Fig. $7 \mathrm{~g}$ ), which corresponds to a large percentage of North Pacific SSTA variance in the decadal time scale (Fig. 2g). Therefore, these results lead us to examine the dynamical process that connects the AMO and PDO in the CESM ATL run more closely.

To examine the impact of the AMO on the PDO, we performed a lead-lag correlation between the AMO and PDO indices in the CESM and MIROC partial assimilation runs (Fig. 10). The AMO index is defined as SSTAs over the North Atlantic $\left(0^{\circ}-60^{\circ} \mathrm{N}, 0^{\circ}-80^{\circ} \mathrm{W}\right)$ subtracted from the global mean $\left(60^{\circ} \mathrm{S}-60^{\circ} \mathrm{N}\right)$ SSTAs as described by Trenberth and Shea (2006). In the GLOB simulations (black lines in Fig. 10a and b), negative (positive) correlations tend to persist more than 10 years when the AMO leads (lags) the PDO, which is consistent with observed correlations (see Figs. 2 and 3 in Wu et al. (2011)). Additionally, we note the statistically significant correlations 11-12 years leading the PDO in the GLOB runs (Zhang and Delworth 2007; Wu et al. 2011); however, these correlations disappear in the CESM and MIROC ATL runs where we find a local peak of correlations when the AMO leads the PDO by 9 months ( $R=-0.77$ and -0.36 , respectively). Using the 9 month lag timeframe, we made correlation maps of SSTA and SLPAs, and regression maps of precipitation and $250 \mathrm{hPa}$ streamfunction anomalies at a 9 months lag with the AMO index in the ATL runs (Fig. 11). We find positive correlations of SSTAs extending from the equatorial Atlantic to Greenland (shaded in Fig. 11a, b), highlighting the strong positive phase of the AMO. This SST warming accompanies negative SLPA correlations over the entire North Atlantic, particularly in the CESM ATL run (Fig. 11a). In the tropical North Atlantic, we can find increases in both precipitation and upper-level pressure (positive streamfunction anomalies) over and north of the warm SSTs (Fig. 11c, d) similar to the findings of Levine et al. (2018) and Wu et al. (2019), where they found that a positive AMO leads to a northward shift in the ITCZ and global Hadley circulation. These results suggest that the SST warming in the tropical North Atlantic associated with the positive phase of the AMO enhances local precipitation activity and leads to the atmospheric dynamical response, such as the baroclinic structure in the tropical North Atlantic and Rossby wave propagation toward extratropical Atlantic. The similar but opposite signs for baroclinic structure and extratropical Rossby wave propagation are also found in the northwestern tropical Pacific in the CESM ATL run (Fig. 11c). At $15^{\circ} \mathrm{N}$, the SST cooling accompanies the decrease in precipitation, higher SLP, and upper-level lower pressure (negative streamfunction anomalies) over the northern tropical Pacific,

\section{(a) CESM}

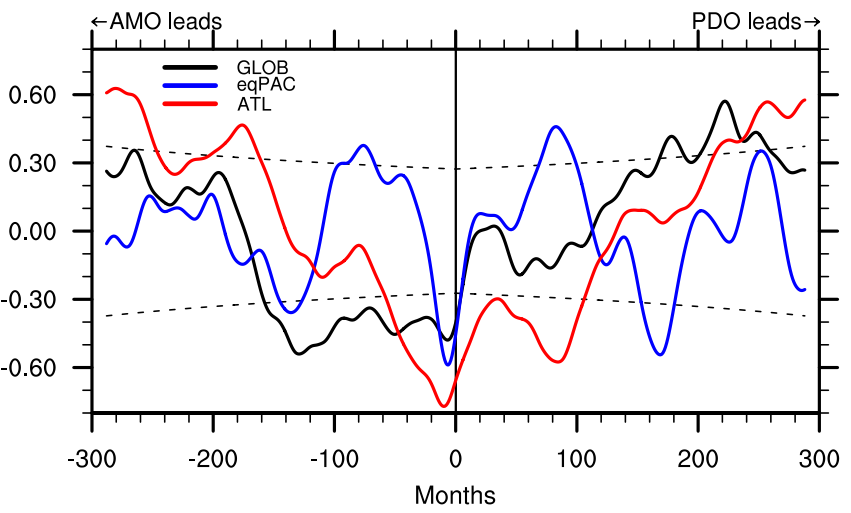

Fig. 10 Lead-lag correlations between the PDO and AMO indices in the GLOB (black), eqPAC (blue), and ATL (red) runs for the (a) CESM and (b) MIROC. Negative (positive) months lag indicates that the AMO leads (lags) the PDO. The Y axis indicates correlation coef-

\section{(b) MIROC}

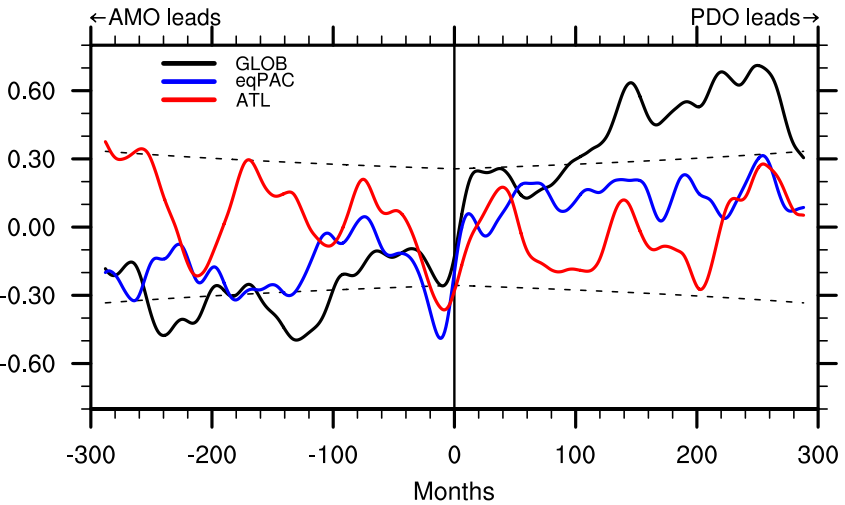

ficients, and the $\mathrm{X}$-axis shows months. A horizontal dashed line indicates a statistical significance at the $95 \%$ confidence level using the two-sided Student's t-test 
CESM ATL

(a) SLP (contours) and SST (colors)

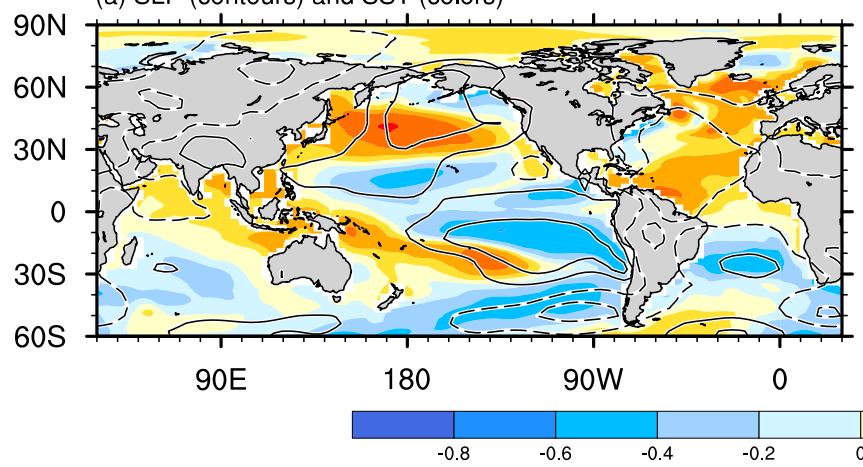

(c) $\Psi 250$ (contours), Precipitation (colors), WAF (arrows)

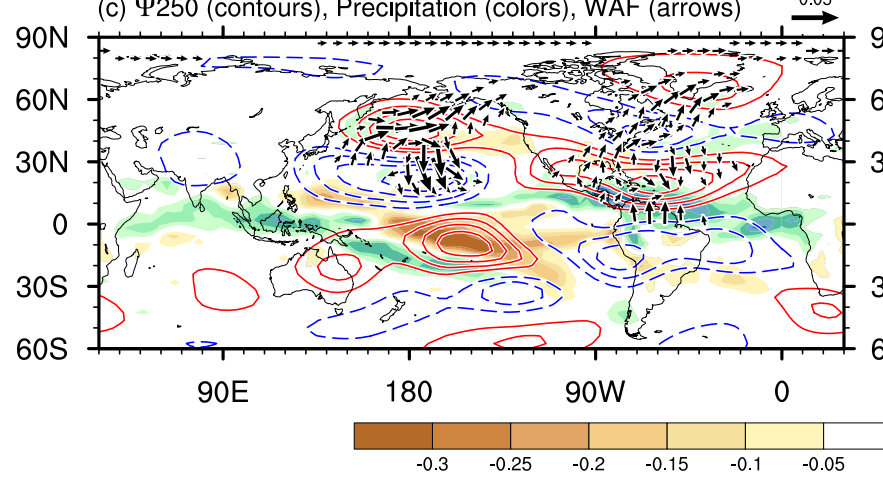

MIROC ATL

(b) SLP (contours) and SST (colors)

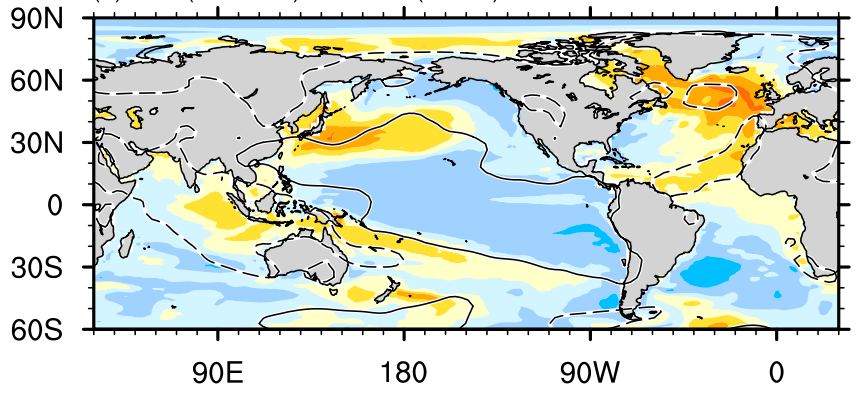

Fig. 11 Correlation maps of SLPAs (contours on top) and SSTAs (shaded on top) and regression maps of precipitation anomalies (shaded on bottom), $250 \mathrm{hPa}$ streamfunction anomalies (solid and broken contours correspond to positive and negative anomalies, respectively), and wave activity flux (vectors on bottom) with the AMO index at 9 months lag for (a, c) CESM and (b, d) MIROC ATL runs. SSTAs have units in ${ }^{\circ} \mathrm{C}$. Precipitation has units in $m m d^{2} y^{-1}$. Vectors (c, d) represent $250 \mathrm{hPa}$ wave-activity flux (units: $\mathrm{m}^{2} \mathrm{~s}^{-2}$ )

which is consistent with Levine et al. (2018). These features, which are unclear in the eqPAC runs of both the CESM and MIROC, highlight the strong north tropical contrast between the Atlantic and Pacific associated with the AMO.

To further examine the inter-basin connection, we produced Hovmöller plots of SST, SLP, precipitation, and $250 \mathrm{hPa}$ zonal wind anomalies over the north tropics $\left(10^{\circ}\right.$ $-20^{\circ} \mathrm{N}$ ) correlated with the AMO index (Fig. 12). Consistent with the correlation maps of SSTA and SLPAs with the AMO index (Fig. 11), we see significant inter-basin contrasts of SSTA and SLPAs between the northern tropical Atlantic and Pacific, particularly in the CESM ATL run (Fig. 12c). Precipitation and upper-level zonal wind anomalies also show the inter-basin contrast in the CESM ATL run with positive precipitation and negative $250 \mathrm{hPa}$ zonal wind anomalies extending from the Atlantic into the eastern Pacific (Fig. 12d). These features suggest that SST warming in the tropical North Atlantic associated with the positive phase of the AMO causes lower SLP, an increase in precipitation, and upper-level easterly wind anomalies over calculated from streamfunctions (contour interval: $0.2 \times 10^{6} \mathrm{~m}^{2} \mathrm{~s}^{-1}$ ) regressed on the AMO index. Solid and broken contours are positive and negative correlations, respectively. A 13-month running mean filter is applied to all anomalies. Reference vectors are denoted in the upper right-hand corner of the bottom plots. Wave-activity fluxes exceeding $0.01 \mathrm{~m}^{2} \mathrm{~s}^{-2}$ are plotted. Note that wave-activity vectors are displayed only in the northern hemisphere

the Caribbean Sea, which leads the atmospheric dynamical response in the subtropical North Pacific. In fact, the timing for the correlation peaks of SST cooling, decreases in precipitation, and upper-level westerly wind anomalies in the subtropical Pacific are several months later than the correlation peaks in the Atlantic (Fig. 12c, d). In the MIROC ATL run (Figs. 11b, d, 12a, b), we can find the same changes of SST, SLP, precipitation, and upper-level zonal wind anomalies as the CESM ATL run, albeit much weaker in amplitude. The reason for this weaker AMO-PDO relationship in the MIROC ATL run is unclear and may arise from model systematic error, mean-state biases, or model climate sensitivity.

\section{Discussion}

Our partial ocean assimilation approach demonstrates that the tropical Pacific is the primary driver for PDO variability, consistent with the atmospheric bridge process 
(a) MIROC - SST (colors) \& SLP (contours)

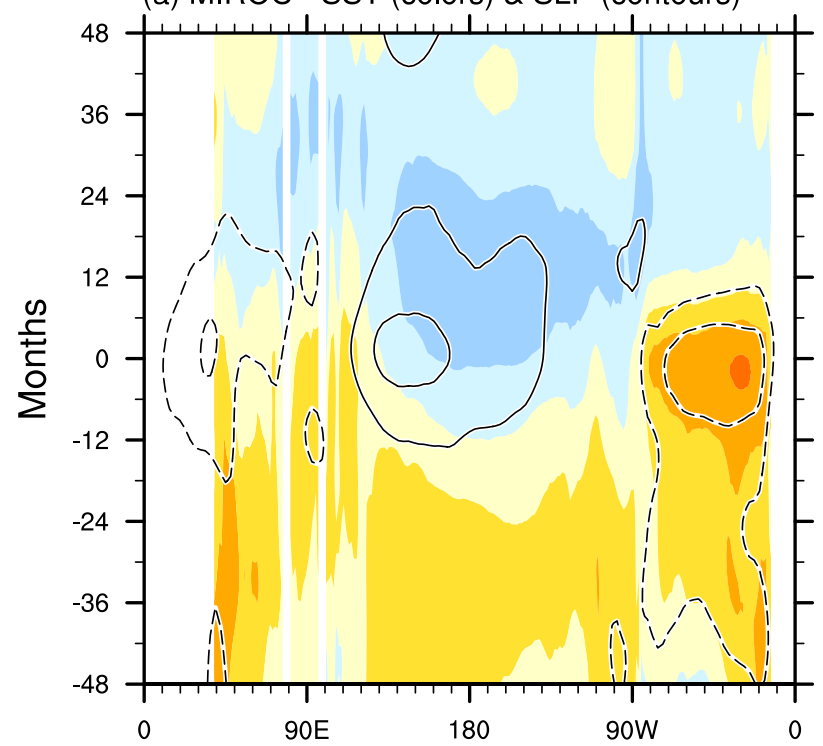

(c) CESM - SST (colors) \& SLP (contours)

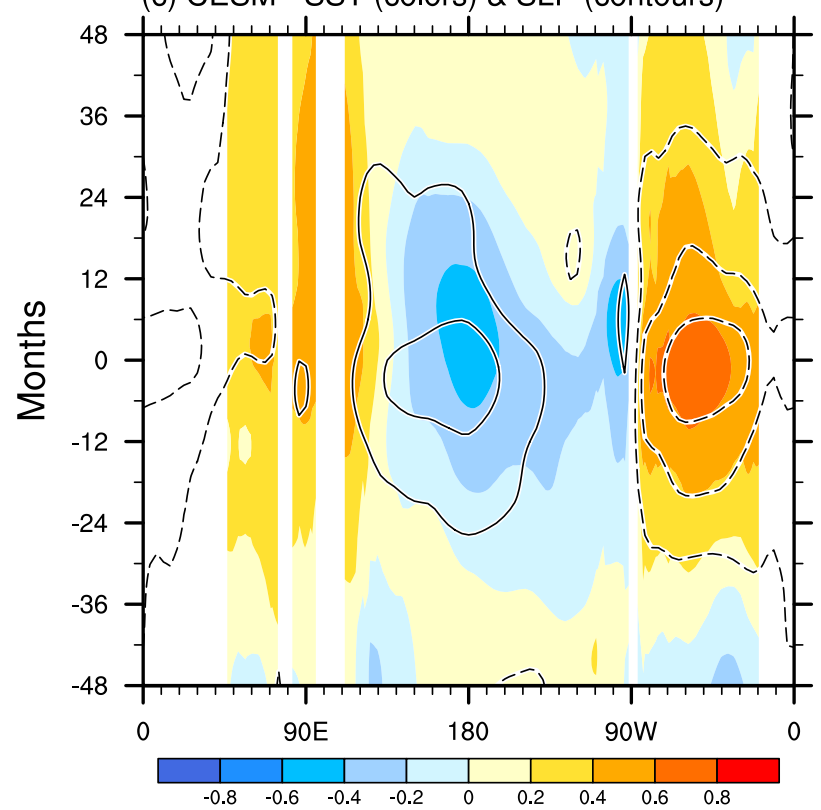

Fig. 12 Hovmöller diagrams for the lead-lag correlation of (a, c) SLP (contours), SST (colors), (b, d) $250 \mathrm{hPa}$ zonal wind (contours), and precipitation anomalies (colors) averaged over the $10^{\circ} \mathrm{N}-20^{\circ} \mathrm{N}$ latitude band with the AMO index in the MIROC (top) and CESM (bot-

proposed by previous studies (Miller et al. 1994; Alexander and Scott 2008; Alexander et al. 2010; Newman et al. 2016). Moving one step further based on our eqPAC runs, we were able to attribute about $40-44 \%$ of PDO variability to the tropical Pacific, similar to the findings of Alexander et al. (2002) and Liu and Alexander (2007). Although the ENSO-PDO relationship in the GLOB runs yields a reduced correlation ranging from $0.60-0.65$ and a time lag ranging from 1-4 months in the CESM and MIROC, (b) MIROC - Precip (colors) \& U250 (contours)

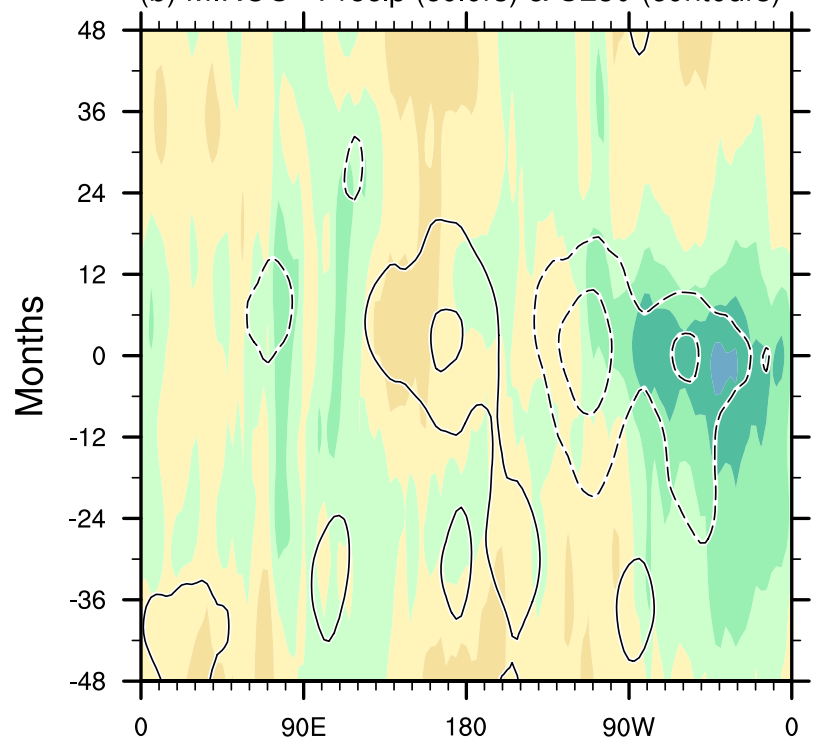

(d) CESM - Precip (colors) \& U250 (contours)

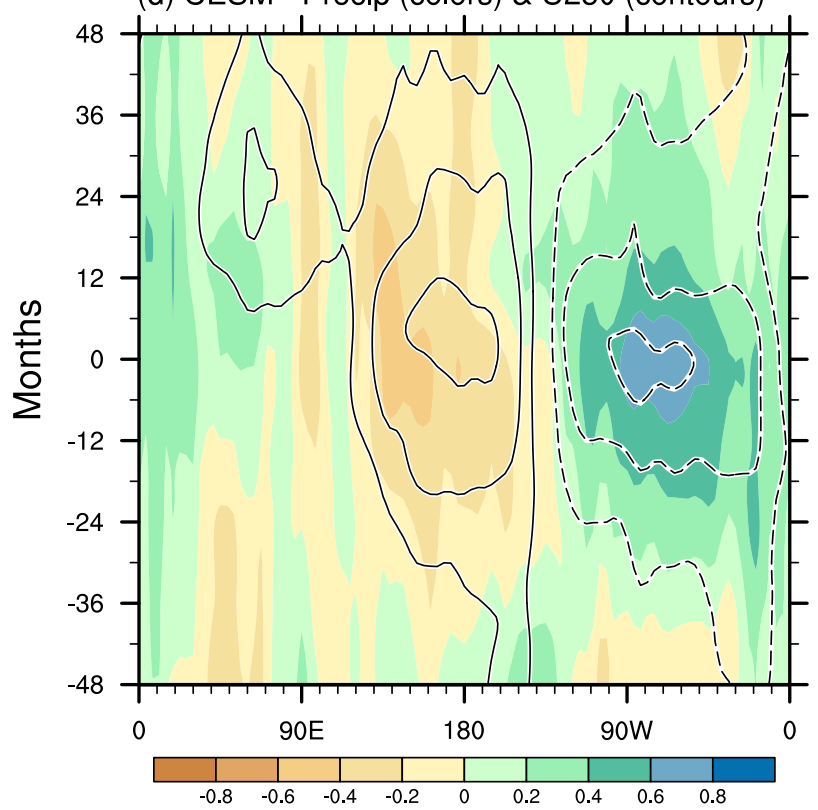

tom) ATL runs. Contour interval is 0.2 with the zero contour omitted. Solid and broken contours are positive and negative correlations, respectively. A 13-month running mean filter is applied to all anomalies

this relationship becomes more consistent in the eqPAC runs with a correlation value of 0.75 and a time lag of 5-7 months. The results of the eqPAC partial assimilations show the following process: equatorial Pacific SST warming enhances local convection activity and then causes a Matsuno-Gill type atmospheric response in the tropical Indo-Pacific region. This atmospheric forcing, in the form of a PNA-like pattern, contributes to the strengthening of Aleutian low variability. As a result, a PDO-like SST 
pattern emerges and persists on interannual-to-decadal timescales.

One of the novel results of this study is that the Atlantic Ocean also affects PDO-like SST variability through two processes: the equatorial and north tropical pathways (Fig. 13). In the equatorial pathway, Atlantic Ocean variability induces changes in the equatorial Pacific through the reorganization of the global Walker circulation, which further affects the PDO through the atmospheric bridge process, as shown by the eqPAC runs (Fig. 13a). This mechanism of the equatorial pathway is consistent with previous studies about the inter-basin interaction between the Atlantic and Pacific (Rodríguez-Fonseca et al. 2009; Ding et al. 2012; Chikamoto et al. 2012; McGregor et al. 2014; Chikamoto et al. 2015b; Kucharski et al. 2016; Li et al. 2015; RuprichRobert et al. 2017; Cai et al. 2019). This equatorial pathway is especially evident in the MIROC ATL run but comparably weak in the CESM ATL run. In contrast to the equatorial pathway, the north tropical pathway emphasizes an AMOinduced inter-basin connection between the north tropical Atlantic and Pacific Oceans (Fig. 13b). In the tropical North Atlantic $\left(10^{\circ}-20^{\circ} \mathrm{N}\right)$, warm AMO SSTs cause increases in precipitation and lead to higher upper-tropospheric pressure through a Matsuno-Gill type atmospheric response

\section{Processes of Atlantic's impact to PDO}

(a) Equatorial Process

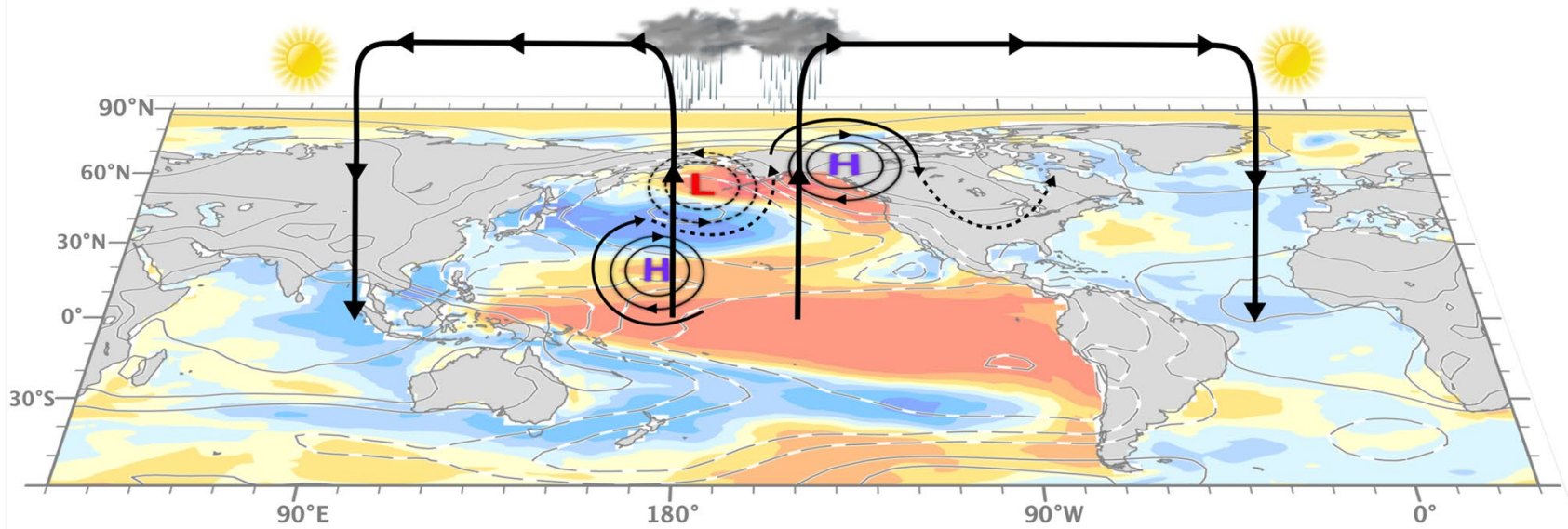

(b) North Tropical Process

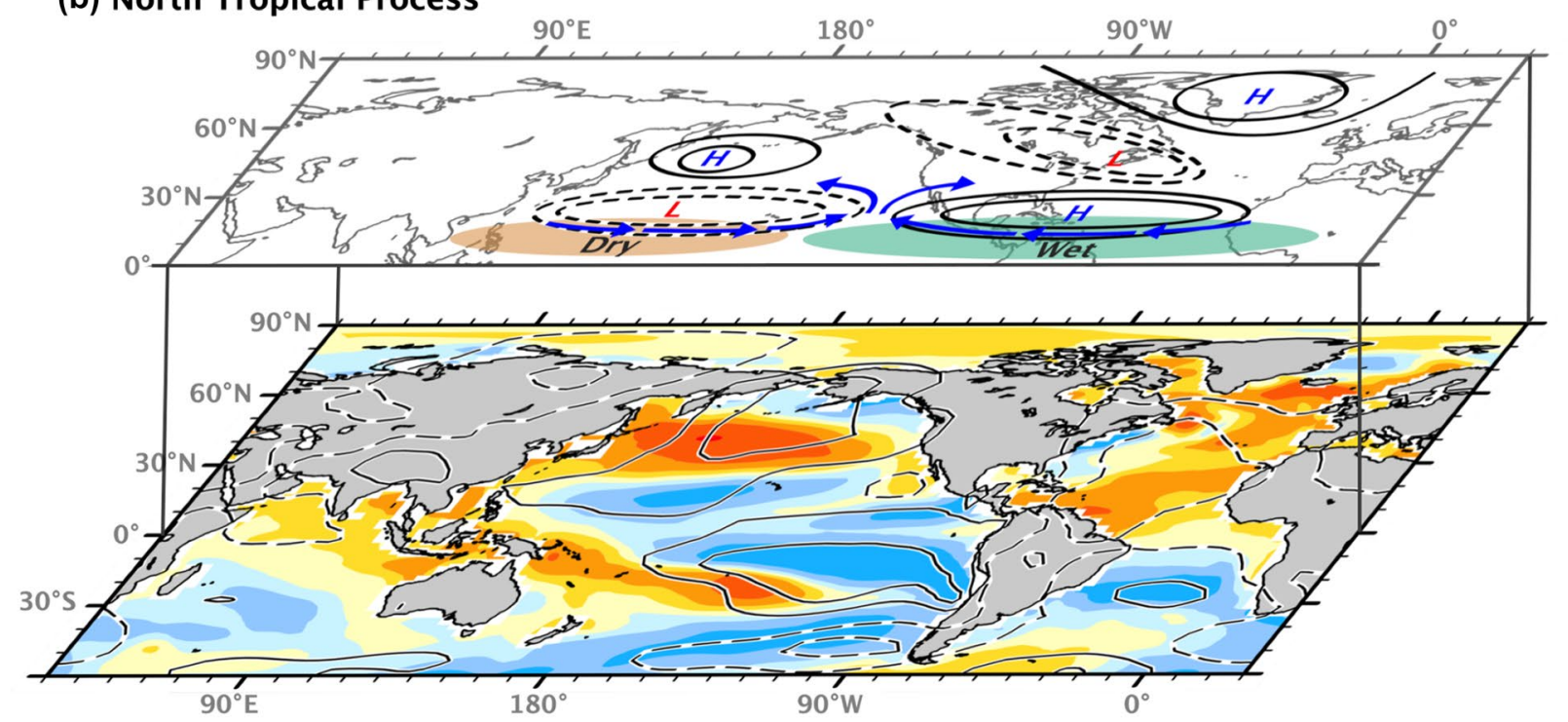

Fig. 13 Schematic figure of (a) the equatorial and (b) north tropical pathways for the Atlantic impact on the PDO. The equatorial pathway highlights the role of the Walker circulation (black vertical and horizontal arrows) and a Rossby wave train. The north tropical pathway is illustrated using the correlation maps of SSTA and SLPAs (bottom) and $250 \mathrm{hPa}$ anomalies of streamfunctions, precipitation, and wind vectors (top) with the AMO index at a 9 months lag 
(Gill 1980). Simultaneously, decreases in precipitation and lower pressure in the upper-troposphere emerge over the northwestern subtropical Pacific through local atmosphere-ocean interactions modulated by the Atlantic forcing. These north tropical atmospheric changes in the Atlantic and Pacific provide energy sources for atmospheric Rossby wave propagation toward the North Pacific resembling the Western Pacific (WP) pattern (Wallace and Gutzler 1981) rather than the PNA pattern. Overall, our ATL runs suggest that $12-29 \%$ of PDO variability originates from Atlantic Ocean variability. Given the strong correlations between the $\mathrm{AMO}$ and the PDO and the associated multi-decadal signal (Liu 2012), it is suggested that persistent AMO forcing may provide a source for the low-frequency component of the PDO variability compared to higher frequency forcing from the equatorial Pacific (Fig. 2g). The north tropical pathway associated with the AMO takes about 1 year to fully impact the PDO, while the equatorial pathway takes about 3 years originating from symmetric equatorial Atlantic SSTAs.

However, a question remains on what accounts for these 1- and 3-year time lags in the north tropical and equatorial pathways from the tropical Atlantic to PDO. According to the atmospheric bridge process in the eqPAC runs, it takes about half a year for ENSO to impact the PDO. In the north tropical pathway, therefore, it is suggested that the process from the tropical Atlantic to the tropical Pacific also takes about a half year. In the equatorial pathway, by contrast, the tropical Atlantic-Pacific process takes significantly longer. In the MIROC ATL run, tropical Atlantic SST cooling and associated high pressure persist 36 months before the PDO with significantly delayed responses in upper-tropospheric westerlies and precipitation over the equatorial Atlantic (Fig. 9b). These delayed atmospheric responses to the tropical Atlantic SST forcing suggest that, in the MIROC, persistent equatorial Atlantic SST forcing is important for driving the local atmospheric response in order to overcome the remote influence from the tropical Pacific. This stronger remote influence in MIROC may explain why the MIROC GLOB run shows tropical Atlantic SST warming associated with the PDO, instead of the tropical Atlantic SST cooling demonstrated by observations and the CESM GLOB run (Fig. 7a-d). This result suggests that uncertainty in our study relates to the model dependency with respect to the strength of the atmospheric response in the tropical Atlantic accounting for local SST forcing and remote impacts.

While this study separates the Atlantic impact on the PDO through two pathways, one at the equator and one at $10^{\circ}-20^{\circ} \mathrm{N}$, the two pathways can involve similar physical processes. According to Li et al. (2015), tropical Atlantic warming can cause the combined changes of the strengthened Pacific Walker circulation, the MatsunoGill type atmospheric response to equatorial forcing, and the activation of Bjerknes feedback. We clearly see this combined response in the equatorial pathway (Fig. 9a, b). In the north tropical pathway, by contrast, we can find the Matsuno-Gill type response to the off-equatorial forcing, but an unclear response in the global Walker circulation and weak activation of Bjerknes feedback, as seen in the weaker response in the equatorial Hovmöller diagram in the CESM ATL (Fig. 9c, d). Furthermore, we can find a different pattern of the atmospheric bridge process: the WP-like pattern in the north tropical pathway and the PNA-like pattern in the equatorial pathway. These results may explain the model diversity regarding the PDO response to Atlantic forcing.

Previous studies found that the AMO negatively correlates with the low-frequency component of the PDO at an 11-12 years lag in addition to a higher frequency component at a 1 year lag (Wu et al. 2011; Zhang and Delworth 2007). Whereas our CESM and MIROC GLOB runs also show a statistically significant peak of negative correlation coefficients between the AMO and PDO indices at about -11 years, with the AMO leading the PDO, this peak disappears in both CESM and MIROC ATL runs (Fig. 10). Regarding the higher frequency component at a 1 year lag, the CESM ATL run shows Rossby wave propagation from the north tropical Atlantic to Greenland (Fig. 10) but no propagation toward the North Pacific across the Eurasian continent (Okumura et al. 2009). Instead of wave propagation, the tropical atmospheric response to the AMO in the CESM ATL run resembles a northward shift in the ITCZ described by Levine et al. (2018). Therefore, our result supports the north tropical pathway through inter-basin interaction rather than a midlatitude pathway through jet stream activities (Zhang and Delworth 2007; Okumura et al. 2009; Zhang and Zhao 2015), or an Arctic Ocean pathway through the Bering Strait (Okumura et al. 2009). Nevertheless, the discrepancy between previous studies and our results may arise from model diversity, seasonal dependency, or analyzed timescales as Zhang and Delworth (2007) found that the AMO can cause changes in the mid-latitude storm track during the boreal winter on multi-decadal timescales based on a GFDL coupled model. Whereas we suggested the AMO impacts on the PDO through the north tropical pathway explain the SLPA dipole between the North Atlantic and North Pacific, other previous studies proposed that the SLP dipole is attributed to mid-latitude zonal circulations based on intermediate complexity coupled models (Sun et al. 2017; Gong et al. 2020). More research is needed to better understand the robustness of and improve performance for the AMOPDO relationship. Important research activities, therefore, include inter-model comparisons using CMIP6 pacemaker experiments (Boer et al. 2016; Ruprich-Robert et al. 2017) as well as partial assimilation experiments using many other climate models. 


\section{Concluding remarks}

This study focuses specifically on the North Pacific region, but the PDO is also related to the Interdecadal Pacific Oscillation (IPO), which spans both northern and southern hemispheres. Since the tropical Pacific strongly impacts southern hemispheric Pacific decadal variability (Folland et al. 2002; Newman et al. 2003; Power and Colman 2006), our mechanism regarding the Atlantic impact on the PDO may be applicable to South Pacific SST variability. Correlation coefficients between the IPO Tripole Index (Henley et al. 2015) with a 13-month running average and our PDO index in ERSST, HadSST, and ProjD are 0.73, 0.75, and 0.73 , respectively. Our ATL CESM and MIROC runs also show significant correlations between those indices $(0.76$ and 0.75), suggesting that our ATL simulations may force decadal variability in the entirety of the Pacific ocean. Future studies need to confirm this relationship.

As others have noted (e.g., Newman et al. 2016), the PDO represents a combination of many atmosphere-ocean processes. Even though tropical Pacific climate variability is the primary driver for the PDO, it is also modulated by multi-basin interactions originating from the Atlantic, as shown by this study. The tropical Pacific and Atlantic basins explain roughly $52-73 \%$ of PDO variability; however, the remaining $27-48 \%$ may originate from regional ocean-atmosphere interactions in the North Pacific itself through locally driven stochastic forcing (Hasselmann 1976; Frankignoul and Hasselmann 1977), a reemergence mechanism (Alexander and Deser 1995; Alexander et al. 1999; Hanawa and Sugimoto 2004), and wind-driven adjustments of the ocean gyre circulation (Miller et al. 1998; Taguchi et al. 2007). Additionally, the Indian Ocean has a potential to affect PDO through the inter-basin interaction between the Indian and tropical Pacific Oceans ( $\mathrm{Yu}$ et al. 2002; Saji and Yamagata 2003; Kug and Kang 2006; Izumo et al. 2010, 2014; Dong and McPhaden 2018). Although we suggest a total of 52-73\% of PDO variability originates from the Atlantic and Pacific independently, this percentage may be lower due to the interdependency of climate modes in each ocean basin. On decadal timescales, specifically, the Atlantic and the Indian Ocean play active roles for tropical Pacific climate variability (Cai et al. 2019), which can affect the PDO through tropical-extratropical teleconnections. The potential for these timescales to be affected by climate change with respect to inter-basin impacts on the PDO needs to be further investigated (Liu 2012; Zhang and Delworth 2016). More studies regarding multi-basin interactions will contribute to advancing our understanding of PDO mechanisms and predictability as well as the recent "hiatus" of global warming (Trenberth 2015), which also involved inter-basin interactions.
Acknowledgements The CESM experiment in this paper was conducted by the University of Southern California Center for HighPerformance Computing and Communications (http://hpcc.usc.edu) and the high-performance computing support from Yellowstone (ark:/85065/d7wd3xhc) and Cheyenne (doi:10.5065/D6RX99HX) provided by NCAR's Computational and Information Systems Laboratory sponsored by the National Science Foundation. The MIROC experiment was supported by the Japanese Ministry of Education, Culture, Sports, Science and Technology, through the Program for Risk Information on Climate Change. The simulations were performed with the Earth Simulator at the Japan Agency for Marine Earth Science and Technology (JAMSTEC). ERSSTv4, HadSST, and NCEP data sets are provided by the NOAA/OAR/ESRL PSD, Boulder, Colorado, USA, from their website at http://www.esrl.noaa.gov/psd/ while ProjD was accessed from JAMSTEC. YC and SYS Wang are supported by the Utah Agricultural Experiment Station, Utah State University (approved as journal paper number 9320) and the Bureau of Reclamation (R18AC00018, R19AP00149). SYS Wang was supported by U.S. Department of Energy Award Number DE-SC0016605 and SERDP Award RC19-F1-1389. MJM is supported by NOAA (PMEL contribution no. 4977). TM was supported by JSPS KAKENHI Grant Numbers JP19H05703 and JP17K05661. Five anonymous reviewers provided helpful comments that improved the quality of this manuscript.

Open Access This article is licensed under a Creative Commons Attribution 4.0 International License, which permits use, sharing, adaptation, distribution and reproduction in any medium or format, as long as you give appropriate credit to the original author(s) and the source, provide a link to the Creative Commons licence, and indicate if changes were made. The images or other third party material in this article are included in the article's Creative Commons licence, unless indicated otherwise in a credit line to the material. If material is not included in the article's Creative Commons licence and your intended use is not permitted by statutory regulation or exceeds the permitted use, you will need to obtain permission directly from the copyright holder. To view a copy of this licence, visit http://creativecommons.org/licenses/by/4.0/.

\section{References}

Alexander M, Blade I, Newman M, Lanzante JR, Lau NC, Scott JD (2002) The atmospheric bridge: the influence of enso teleconnections on air-sea interaction over the global oceans. J Clim 15:2205-2231

Alexander M et al (2010) Extratropical air-sea interaction, sea surface temperature variability, and the pacific decadal oscillation. Climate dynamics: Why does climate vary? Geophys Monogr 189:123-148

Alexander MA (1990) Simulation of the response of the north pacific ocean to the anomalous atmospheric circulation associated with el niño. Clim Dyn 5(1):53-65

Alexander MA, Deser C (1995) A mechanism for the recurrence of wintertime midlatitude sst anomalies. J Phys Oceanog 25(1):122-137

Alexander MA, Scott JD (2008) The role of ekman ocean heat transport in the northern hemisphere response to enso. J Clim 21(21):5688-5707

Alexander MA, Deser C, Timlin MS (1999) The reemergence of sst anomalies in the north pacific ocean. J Clim 12(8):2419-2433

Alexander MA, Lau NC, Scott JD (2004) Broadening the atmospheric bridge paradigm: ENSO teleconnections to the tropical west Pacific-Indian Oceans over the seasonal cycle and to the North Pacific in summer. Earth Climate: Ocean-atmosphere interaction 
and climate variability 147:85-103, geophysical Monograph, AGU, Washington D. C

Alexander MA, Matrosova L, Penland C, Scott JD, Chang P (2008) Forecasting pacific ssts: linear inverse model predictions of the pdo. J Clim 21(2):385-402

Balmaseda MA, Mogensen K, Weaver AT (2013) Evaluation of the ecmwf ocean reanalysis system oras4. Q J R Meteorol Soc 139(674):1132-1161

Barlow M, Nigam S, Berbery EH (2001) Enso, pacific decadal variability, and us summertime precipitation, drought, and stream flow. J Clim 14(9):2105-2128

Bloom SC, Takacs L, da Silva AM, Ledvina D (1996) Data assimilation using incremental analysis updates. Mon Wea Rev 124:1256-1271

Boer GJ, Smith DM, Cassou C, Doblas-Reyes F, Danabasoglu G, Kirtman B, Kushnir Y, Kimoto M, Meehl GA, Msadek R et al (2016) The decadal climate prediction project (dcpp) contribution to cmip6. Geoscientific Model Dev 9(10):3751-3777

Bretherton CS, Widmann M, Dymnikov VP, Wallace JM, Bladé I (1999) The effective number of spatial degrees of freedom of a time-varying field. J Clim 12(7):1990-2009

Cai W, Wu L, Lengaigne M, Li T, McGregor S, Kug JS, Yu JY, Stuecker MF, Santoso A, Li X, Ham YG, Chikamoto Y, Ng B, McPhaden MJ, Du Y, Dommenget D, Jia F, Kajtar JB, Keenlyside N, Lin X, Luo JJ, Martín-Rey M, Ruprich-Robert Y, Wang G, Xie SP, Yang Y, Kang SM, Choi JY, Gan B, Kim GI, Kim CE, Kim S, Kim JH, Chang P (2019) Pantropical climate interactions. Science 363(6430):944-954

Chang P, Yamagata T, Schopf P, Behera SK, Carton J, Kessler WS, Meyers G, Qu T, Schott F, Shetye S, Xie SP (2006) Climate fluctuations of tropical coupled systems-the role of ocean dynamics. J Clim 19(20):5122-5174. https://doi.org/10.1175/ JCLI3903.1

Chavez FP, Ryan J, Lluch-Cota SE, Niquen M (2003) From anchovies to sardines and back: multidecadal change in the pacific ocean. Science 299(5604):217-221

Chiang JCH, Lintner BR (2005) Mechanisms of remote tropical surface warming during El Nino. J Clim 18:4130-4149

Chiang JCH, Sobel AH (2002) Tropical tropospheric temperature variations caused by ENSO and their influence on the remote tropical climate. J Clim 15:2616-2631

Chikamoto MO, Timmermann A, Chikamoto Y, Tokinaga H, Harada N (2015a) Mechanisms and predictability of multiyear ecosystem variability in the North Pacific. Global Biogeochem Cycles 29:2001-2019. https://doi.org/10.1002/2015GB005096

Chikamoto Y, Tanimoto Y (2005) Role of specific humidity anomalies in Caribbean SST response to ENSO. J Meteorol Soc Jpn 83:959-975

Chikamoto Y, Kimoto M, Watanabe M, Ishii M, Mochizuki T (2012) Relationship between the Pacific and Atlantic stepwise climate change during the 1990s. Geophys Res Lett 39(21):L21,710. https://doi.org/10.29/2012GL053901

Chikamoto Y, Kimoto M, Ishii M, Mochizuki T, Sakamoto TT, Tatebe H, Komuro Y, Watanabe M, Nozawa T, Shiogama H et al (2013) An overview of decadal climate predictability in a multi-model ensemble by climate model MIROC. Clim Dyn 40:1201-1222

Chikamoto Y, Timmermann A, Luo JJ, Mochizuki T, Kimoto M, Watanabe M, Ishii M, Xie SP, Jin FF (2015b) Skilful multi-year predictions of tropical trans-basin climate variability. Nat Commun 6:6869

Chikamoto Y, Timmermann A, Stevenson S, DiNezio P, Langford S (2015c) Decadal predictability of soil water, vegetation, and wildfire frequency over North America. Clim Dyn 45:2213-2235

Chikamoto Y, Mochizuki T, Timmermann A, Kimoto M, Watanabe M (2016) Potential tropical atlantic impacts on pacific decadal climate trends. Geophys Res Lett 43(13):7143-7151
Chikamoto Y, Timmerman A, Widlansky MJ, Zhang S, Balmaseda MA (2019) A drift-free climate prediction system for the community earth system model. J Clim. https://doi.org/10.1175/ JCLI-D-18-0788.1

Deser C, Phillips AS, Hurrell JW (2004) Pacific interdecadal climate variability: Linkages between the tropics and the north pacific during boreal winter since 1900. J Clim 17(16):3109-3124

Di Lorenzo E, Schneider N, Cobb K, Franks P, Chhak K, Miller A, McWilliams J, Bograd S, Arango H, Curchitser E et al (2008) North pacific gyre oscillation links ocean climate and ecosystem change. Geophys Res Lett 35(8):L08,607. https://doi. org/10.1029/2007GL032838

Di Lorenzo E, Liguori G, Schneider N, Furtado J, Anderson B, Alexander M (2015) Enso and meridional modes: A null hypothesis for pacific climate variability. Geophys Res Lett 42(21):9440-9448

Ding H, Keenlyside NS, Latif M (2012) Impact of the equatorial atlantic on the el niño southern oscillation. Clim Dyn 38(9-10):1965-1972

Dong L, McPhaden MJ (2017) The role of external forcing and internal variability in regulating global mean surface temperatures on decadal timescales. Environ Res Lett 12(3):034,011

Dong L, McPhaden MJ (2018) Unusually warm indian ocean sea surface temperatures help to arrest development of el niño in 2014. Sci Rep 8(1):2249

Ebita A, Kobayashi S, Ota Y, Moriya M, Kumabe R, Onogi K, Harada Y, Yasui S, Miyaoka K, Takahashi K et al (2011) The japanese 55-year reanalysis "jra-55": an interim report. Sola 7:149-152

Folland C, Renwick J, Salinger M, Mullan A (2002) Relative influences of the interdecadal pacific oscillation and enso on the south pacific convergence zone. Geophys Res Lett 29(13):21-1

Francis RC, Hare SR (1994) Decadal-scale regime shifts in the large marine ecosystems of the north-east pacific: a case for historical science. Fish Oceanogr 3(4):279-291

Frankignoul C, Hasselmann K (1977) Stochastic climate models, part ii. application to sea-surface temperature anomalies and thermocline variability. Tellus 29:289-305

Gill AE (1980) Some simple solutions for heat-induced tropical circulation. Q J Roy Meteorol Soc 106:447-462

Gong Z, Sun C, Li J, Feng J, Xie F, Ding R, Yang Y, Xue J (2020) An inter-basin teleconnection from the north atlantic to the subarctic north pacific at multidecadal time scales. Clim Dyn 54(1-2):807-822

Ham YG, Kug JS (2015) Role of north tropical atlantic sst on the enso simulated using cmip3 and cmip5 models. Clim Dyn 45(11-12):3103-3117

Ham YG, Kug JS, Park JY (2013a) Two distinct roles of atlantic ssts in enso variability: North tropical atlantic sst and atlantic niño. Geophys Res Lett 40(15):4012-4017

Ham YG, Kug JS, Park JY, Jin FF (2013b) Sea surface temperature in the north tropical atlantic as a trigger for el niño/southern oscillation events. Nat Geosci 6(2):112

Ham YG, Chikamoto Y, Kug JS, Kimoto M, Mochizuki T (2017) Tropical atlantic-korea teleconnection pattern during boreal summer season. Clim Dyn 49(7-8):2649-2664

Hanawa K, Sugimoto S (2004) 'Reemergence' areas of winter sea surface temperature anomalies in the world's oceans. Geophys Res Lett. https://doi.org/10.1029/2004GL019904

Hasselmann K (1976) Stochastic climate models. part i. theory. Tellus 28:473-485

Henley BJ, Gergis J, Karoly DJ, Power S, Kennedy J, Folland CK (2015) A tripole index for the interdecadal pacific oscillation. Clim Dyn 45(11-12):3077-3090

Holland MM, Bailey DA, Briegleb BP, Light B, Hunke E (2012) Improved sea ice shortwave radiation physics in ccsm4: the 
impact of melt ponds and aerosols on arctic sea ice. J Clim 25(5):1413-1430

Hu ZZ, Huang B (2009) Interferential impact of enso and pdo on dry and wet conditions in the us great plains. J Clim 22(22):6047-6065

Huang B, Kinter J, Schopf P (2002) Ocean data assimilation using intermittent analyses and continuous model error correction. Adv Atmos Sci 19(6):965-992

Huang B, Banzon VF, Freeman E, Lawrimore J, Liu W, Peterson TC, Smith TM, Thorne PW, Woodruff SD, Zhang HM (2015) Extended reconstructed sea surface temperature version 4 (ERSST. v4). Part I: upgrades and intercomparisons. J Clim 28(3):911-930

Hunke E, Lipscomb W (2008) Cice: the los alamos sea ice model user's manual, version 4, los alamos natl. Tech. rep., Lab. Tech. Report, LA-CC-06-012, Los Alamos, NM, USA

Ishii M, Kimoto M (2009) Reevaluation of historical ocean heat content variations with time-varying XBT and MBT depth bias corrections. J Oceanogr 65(3):287-299

Izumo T, Vialard J, Lengaigne M, de Boyer Montegut C, Behera SK, Luo JJ, Cravatte S, Masson S, Yamagata T (2010) Influence of the state of the indian ocean dipole on the following year's el niño. Nat Geosci 3(3):168

Izumo T, Lengaigne M, Vialard J, Luo JJ, Yamagata T, Madec G (2014) Influence of indian ocean dipole and pacific recharge on following year's el niño: interdecadal robustness. Clim Dyn 42(1-2):291-310

Johnson Z, Chikamoto Y, Luo JJ, Mochizuki T (2018) Ocean impacts on australian interannual to decadal precipitation variability. Climate 6(3):61

Kennedy J, Rayner N, Smith R, Parker D, Saunby M (2011a) Reassessing biases and other uncertainties in sea surface temperature observations measured in situ since 1850: 1. measurement and sampling uncertainties. J Geophys Res Atmos 116(D14):D14103

Kennedy J, Rayner N, Smith R, Parker D, Saunby M (2011b) Reassessing biases and other uncertainties in sea surface temperature observations measured in situ since 1850: 2 . biases and homogenization. J Geophys Res 116(D14):D14104

Kim HM, Ham YG, Scaife AA (2014) Improvement of initialized decadal predictions over the north pacific ocean by systematic anomaly pattern correction. J Clim 27(2014):5148-5162. https ://doi.org/10.1175/JCLI-D-13-00519.1

Knight J, Allan R, Folland C, Vellinga M, Mann M (2005) A signature of persistent natural thermohaline circulation cycles in observed climate. Geophys Res Lett 32(L20):708

Kosaka Y, Xie SP (2013) Recent global-warming hiatus tied to equatorial Pacific surface cooling. Nature 501(7467):403-407

Kucharski F, Kang I, Farneti R, Feudale L (2011) Tropical Pacific response to 20th century Atlantic warming. Geophys Res Lett 38(L03):702

Kucharski F, Ikram F, Molteni F, Farneti R, Kang IS, No HH, King MP, Giuliani G, Mogensen K (2016) Atlantic forcing of pacific decadal variability.Clim. Dyn 46(7-8):2337-2351

Kug JS, Kang IS (2006) Interactive feedback between enso and the indian ocean. J Clim 19(9):1784-1801

Kwon YO, Deser C (2007) North pacific decadal variability in the community climate system model version 2 . J Clim 20(11):2416-2433

Lau NC, Nath MJ (1994) A modeling study of the relative roles of tropical and extratropical sst anomalies in the variability of the global atmosphere-ocean system. J Clim 7:1184-1207

Lau NC, Nath MJ (1996) The role of the 'atmospheric bridge' in linking tropical pacific enso events to extratropical sst anomalies. J Clim 9:2036-2057
Lawrence DM, Oleson KW, Flanner MG, Fletcher CG, Lawrence PJ, Levis S, Swenson SC, Bonan GB (2012) The ccsm4 land simulation, 1850-2005: assessment of surface climate and new capabilities. J Clim 25(7):2240-2260

Levine AF, Frierson DM, McPhaden MJ (2018) Amo forcing of multidecadal pacific itcz variability. J Clim 31(14):5749-5764

Li X, Xie SP, Gille ST, Yoo C (2015) Atlantic-induced pan-tropical climate change over the past three decades. Nat Clim Change. https://doi.org/10.1038/nclimate2840

Liu Z (2012) Dynamics of interdecadal climate variability: a historical perspective. J Clim 25(6):1963-1995

Liu Z, Alexander M (2007) Atmospheric bridge, oceanic tunnel, and global climatic teleconnections. Rev Geophys 45(2):RG2005

Luo JJ, Zhang R, Behera SK, Masumoto Y, Jin FF, Lukas R, Yamagata $\mathrm{T}$ (2010) Interaction between el nino and extreme indian ocean dipole. J Clim 23(3):726-742

Luo JJ, Liu G, Hendon H, Alves O, Yamagata T (2017) Inter-basin sources for two-year predictability of the multi-year la niña event in 2010-2012. Sci Rep 7(1):2276

Mantua NJ, Hare SR (2002) The pacific decadal oscillation. J Oceanogr $58: 35-44$

Mantua NJ, Hare SR, Zhang Y, Wallace JM, Francis RC (1997) A Pacific interdecadal climate oscillation with impacts on salmon production. Bull Amer Meteorol Soc 78:1069-1079

McCabe GJ, Palecki MA, Betancourt JL (2004) Pacific and Atlantic Ocean influences on multidecadal drought frequency in the United States. Proc Natl Acad Sci USA 101(12):4136

McGregor S, Timmermann A, Stuecker MF, England MH, Merrifield M, Jin FF, Chikamoto Y (2014) Recent Walker circulation strengthening and Pacific cooling amplified by Atlantic warming. Nat Clim Change 4(10):888-892

Miller AJ, Cayan DR, Barnett TP, Graham NE, Oberhuber JM (1994) Interdecadal variability of the pacific ocean: model response to observed heat flux and wind stress anomalies. Clim Dyn 9(6):287-302

Miller AJ, Cayan DR, White WB (1998) A westward-intensified decadal change in the north pacific thermocline and gyre-scale circulation. J Clim 11(12):3112-3127

Minobe S (1997) A 50-70 year climatic oscillation over the north pacific and north america. Geophys Res Lett 24(6):683-686

Mochizuki T, Ishii M, Kimoto M, Chikamoto Y, Watanabe M, Nozawa T, Sakamoto TT, Shiogama H, Awaji T, Sugiura N, Toyoda T, Yasunaka S, Tatebe H (1833) Mori M (2010) Pacific decadal oscillation hindcasts relevant to near-term climate prediction. Proc Natl Acad Sci USA 107:1833-1837

Nakamura H, Lin G, Yamagata T (1997) Decadal climate variability in the noryj pacific during the recent decades. Bull Amer Meteorol Soc 78:2215-2225

Neale RB, Richter J, Park S, Lauritzen PH, Vavrus SJ, Rasch PJ, Zhang M (2013) The mean climate of the community atmosphere model (cam4) in forced sst and fully coupled experiments. J Clim 26(14):5150-5168

Newman M, Compo GP, Alexander MA (2003) Enso-forced variability of the pacific decadal oscillation. J Clim 16(23):3853-3857

Newman M, Alexander MA, Ault TR, Cobb KM, Deser C, Di Lorenzo E, Mantua NJ, Miller AJ, Minobe S, Nakamura H et al (2016) The pacific decadal oscillation, revisited. J Clim 29(12):4399-4427

Nidheesh A, Lengaigne M, Vialard J, Izumo T, Unnikrishnan A, Cassou $C$ (2017) Influence of enso on the pacific decadal oscillation in cmip models. Clim Dyn 49(9-10):3309-3326

Nozawa T, Nagashima T, Ogura T, Yokohata T, Okada N, Shiogama H (2007) Climate change simulations with a coupled ocean-atmosphere GCM called the model for interdisciplinary research on climate: MIROC. CGER Supercomput Monogr Rep 12, cent. 
for Global Environ. Res., Natl. Inst. for Environ. Stud., Tsukuba, Japan

Okumura YM, Deser C, Hu A, Timmermann A, Xie SP (2009) North Pacific climate response to freshwater forcing in the subarctic North Atlantic: Oceanic and atmospheric pathways. J Clim 22(6):1424-1445

Oshima K, Tanimoto Y (2009) An evaluation of reproducibility of the pacific decadal oscillation in the cmip3 simulations. J Meteorol Soc Jpn Ser II 87(4):755-770

Power S, Colman R (2006) Multi-year predictability in a coupled general circulation model. Clim Dyn 26(2-3):247-272

Purich A, England MH, Cai W, Chikamoto Y, Timmermann A, Fyfe JC, Frankcombe L, Meehl GA, Arblaster JM (2016) Tropical pacific sst drivers of recent antarctic sea ice trends. J Clim 29(24):8931-8948

Qiu B (2002) The kuroshio extension system: Its large-scale variability and role in the midlatitude ocean-atmosphere interaction. $\mathrm{J}$ Oceanogr 58(1):57-75

Qiu B, Schneider N, Chen S (2007) Coupled decadal variability in the north pacific: an observationally constrained idealized model. J Clim 20(14):3602-3620

Rodríguez-Fonseca B, Polo I, García-Serrano J, Losada T, Mohino E, Mechoso CR, Kucharski F (2009) Are atlantic niños enhancing pacific enso events in recent decades? Geophys Res Lett. https:// doi.org/10.1029/2009GL040048

Ruprich-Robert Y, Msadek R, Castruccio F, Yeager S, Delworth T, Danabasoglu G (2017) Assessing the climate impacts of the observed atlantic multidecadal variability using the gfdl $\mathrm{cm} 2.1$ and ncar cesm1 global coupled models. J Clim 30(8):2785-2810

Saji N, Yamagata T (2003) Possible impacts of indian ocean dipole mode events on global climate. Clim Res 25(2):151-169

Shields CA, Bailey DA, Danabasoglu G, Jochum M, Kiehl JT, Levis S, Park S (2012) The low-resolution ccsm4. J Clim 25(12):3993-4014

Smith R, Jones P, Briegleb B, Bryan F, Danabasoglu G, Dennis J, Dukowicz J, Eden C, Fox-Kemper B, Gent P, et al. (2010) The parallel ocean program (pop) reference manual: ocean component of the community climate system model (ccsm) and community earth system model (cesm). Rep LAUR-01853 141:1-140

Sobel AH, Held IM, Bretherton CS (2002) The enso signal in tropical tropospheric temperature. J Clim 15:2702-2706

Strong C, Magnusdottir G (2009) The role of tropospheric rossby wave breaking in the pacific decadal oscillation. J Clim 22(7):1819-1833

Sun C, Kucharski F, Li J, Jin FF, Kang IS, Ding R (2017) Western tropical pacific multidecadal variability forced by the atlantic multidecadal oscillation. Nat Commun 8(1):1-10

Taguchi B, Xie SP, Schneider N, Nonaka M, Sasaki H, Sasai Y (2007) Decadal variability of the kuroshio extension: observations and an eddy-resolving model hindcast. J Clim 20(11):2357-2377

Taguchi B, Nakamura H, Nonaka M, Komori N, Kuwano-Yoshida A, Takaya K, Goto A (2012) Seasonal evolutions of atmospheric response to decadal sst anomalies in the north pacific subarctic frontal zone: observations and a coupled model simulation. $\mathbf{J}$ Clim 25(1):111-139

Takaya K, Nakamura H (2001) A formulation of a phase-independent wave-activity flux for stationary and migratory quasigeostrophic eddies on a zonally varying basic flow. J Atmos Sci 58:608-627

Tanimoto Y, Nakamura H, Kagimoto T, Yamane S (2003) An active role of extratropical sea surface temperature anomalies in determining anomalous turbulent heat flux. J Geophys Res 108:3304. https://doi.org/10.1029/2002JC001750

Taschetto AS, Haarsma RJ, Gupta AS, Ummenhofer CC, Hill KJ, England MH (2010) Australian monsoon variability driven by a gill-matsuno-type response to central west pacific warming. $\mathrm{J}$ Clim 23(18):4717-4736
Trenberth KE (2015) Has there been a hiatus? Science 349(6249):691-692

Trenberth KE, Hurrell JW (1994) Decadal atmosphere-ocean variations in the pacific. Clim Dyn 9:303-319

Trenberth KE, Shea DJ (2006) Atlantic hurricanes and natural variability in 2005. Geophys Res Lett 33(12):L12,704

Trenberth KE, Branstator GW, Karoly D, Kumar A, Lau NC, Ropelewski C (1998) Progress during TOGA in understanding and modeling global teleconnections associated with tropical sea surface temperatures. J Geophys Res 103:14,291-14,324

Vance T, Roberts J, Plummer C, Kiem A, Van Ommen T (2015) Interdecadal pacific variability and eastern australian megadroughts over the last millennium. Geophys Res Lett 42(1):129-137

Wallace JM, Gutzler DS (1981) Teleconnections in the geopotential height field during the northern hemisphere winter. Mon Wea Rev 109:784-812

Wang H, Kumar A, Wang W, Xue Y (2012) Influence of enso on pacific decadal variability: an analysis based on the ncep climate forecast system. J Clim 25(18):6136-6151

Wang S, Huang J, He Y, Guan Y (2014) Combined effects of the pacific decadal oscillation and el nino-southern oscillation on global land dry-wet changes. Sci Rep 4(srep06):651

Wang SY, Gillies RR, Jin J, Hipps LE (2009) Recent rainfall cycle in the intermountain region as a quadrature amplitude modulation from the pacific decadal oscillation. Geophys Res Lett 36(2):L02705

Wu CR, Lin YF, Qiu B (2019) Impact of the atlantic multidecadal oscillation on the pacific north equatorial current bifurcation. Sci Rep 9(1):2162

Wu S, Liu Z, Zhang R, Delworth TL (2011) On the observed relationship between the pacific decadal oscillation and the atlantic multi-decadal oscillation. J Oceanogr 67(1):27-35

Yu B, Zwiers F (2007) The impact of combined enso and pdo on the pna climate: a 1000-year climate modeling study. Clim Dyn 29(7-8):837-851

Yu JY, Mechoso CR, McWilliams JC, Arakawa A (2002) Impacts of the indian ocean on the enso cycle. Geophys Res Lett 29(8):46-1

Zanchettin D, Franks SW, Traverso P, Tomasino M (2008) On enso impacts on european wintertime rainfalls and their modulation by the nao and the pacific multi-decadal variability described through the pdo index. Int J Clim 28(8):995-1006

Zhang L, Delworth TL (2015) Analysis of the characteristics and mechanisms of the pacific decadal oscillation in a suite of coupled models from the geophysical fluid dynamics laboratory. J Clim 28(19):7678-7701

Zhang L, Delworth TL (2016) Simulated response of the pacific decadal oscillation to climate change. J Clim 29(16):5999-6018

Zhang L, Zhao C (2015) Processes and mechanisms for the model sst biases in the $\mathrm{n}$ orth a tlantic and $\mathrm{n}$ orth $\mathrm{p}$ acific: a link with the a tlantic meridional overturning circulation. J Adv Modeling Earth Syst 7(2):739-758

Zhang R, Delworth TL (2007) Impact of the atlantic multidecadal oscillation on north pacific climate variability. Geophys Res Lett 34(23):L23708

Zhang RH, Levitus S (1997) Structure and cycle of decadal variability of upper-ocean temperature in the north pacific. J Clim 10(4):710-727

Zhang Y, Xie SP, Kosaka Y, Yang JC (2018) Pacific decadal oscillation: tropical pacific forcing versus internal variability. J Clim 31(20):8265-8279

Publisher's Note Springer Nature remains neutral with regard to jurisdictional claims in published maps and institutional affiliations. 